\title{
Differential host gene responses from infection with neurovirulent and partially- neurovirulent strains of Venezuelan equine encephalitis virus
}

Paridhi Gupta', Anuj Sharma ${ }^{1 *}$, Jing Han², Amy Yang ${ }^{2}$, Manish Bhomia', Barbara Knollmann-Ritschel',

Raj K Puri ${ }^{2}$ and Radha K Maheshwari ${ }^{1 \wedge}$

\begin{abstract}
Background: Venezuelan equine encephalitis virus (VEEV) is an alphavirus in the family Togaviridae. VEEV causes a bi-phasic illness in mice where primary replication in lymphoid organs is followed by entry into the central nervous system (CNS). The CNS phase of infection is marked by encephalitis and large scale neuronal death ultimately resulting in death. Molecular determinants of VEEV neurovirulence are not well understood. In this study, host gene expression response to highly neurovirulent VEEV (V3000 strain) infection was compared with that of a partially neurovirulent VEEV (V3034 strain) to identify host factors associated with VEEV neurovirulence.

Methods: Whole genome microarrays were performed to identify the significantly modulated genes. Microarray observations were classified into three categories i.e., genes that were similarly modulated against both V3000 and V3034 infections, and genes that were uniquely modulated in infection with V3034 or V3000. Histologic sections of spleen and brain were evaluated by hematoxylin and eosin stains from all the mice.

Results: V3000 infection induced a greater degree of pathology in both the spleen and brain tissue of infected mice compared to V3034 infection. Genes commonly modulated in the spleens after V3000 or V3034 infection were associated with innate immune responses, inflammation and antigen presentation, however, V3000 induced a gene response profile that suggests a stronger inflammatory and apoptotic response compared to V3034. In the brain, both the strains of VEEV induced an innate immune response reflected by an upregulation of the genes involved in antigen presentation, interferon response, and inflammation. Similar to the spleen, V3000 was found to induce a stronger inflammatory response than V3034 in terms of induction of pro-inflammatory genes and associated pathways. CCl2, CCl5, CCl6, and Ly6 were uniquely upregulated in V3000 infected mouse brains and correlated with the extensive inflammation observed in the brain.

Conclusion: The common gene profile identified from V3000 and V3034 exposure can help in understanding a generalized host response to VEEV infection. Inflammatory genes that were uniquely identified in mouse brains with V3000 infection will help in better understanding the lethal neurovirulence of VEEV. Future studies are needed to explore the roles played by the genes identified in VEEV induced encephalitis.
\end{abstract}

Keywords: Venezuelan equine encephalitis virus, Host responses, Whole genome microarray, Neurovirulence, V3000, V3034

\footnotetext{
* Correspondence: anuj.sharma.ctr@usuhs.edu

Deceased

'Department of Pathology, Uniformed Services University of the Health

Sciences, 4301 Jones Bridge Road, Bethesda, MD 20814, USA

Full list of author information is available at the end of the article
} 


\section{Background}

Venezuelan equine encephalitis virus (VEEV) is a highly infectious emerging pathogen of bioterrorism interest. VEEV is an arthropod borne virus in the family Togaviridae. VEEV causes a characteristic bi-phasic illness where the primary replication in lymphoid tissues is followed by viral replication in central nervous system (CNS) (Johnston and Peter, 1996). CNS infection is dependent on the ability of VEEV to replicate to a high titer in the circulation, which helps the escape of the virus from the blood circulation into the fenestrated neuroepithelium of the olfactory tract, and ultimately into the olfactory lobe of the brain [1-3]. Once in brain, VEEV replicates in the neurons and glia and spreads centripetally from olfactory lobe to the mid brain and cerebellum [2]. Mortality in humans is low $(<1 \%)$, but in equines VEEV can cause mortality as high as $83 \%$ [4]. Severe morbidity and mortality is associated with viral replication in CNS, as well as possible permanent long term neurological deficits [5]. Within the CNS, excessive inflammation has been suggested to contribute to increased neuronal and glial cell death in addition to direct neuronal cell death from VEEV infection [6, 7]. VEEV infection has been shown to induce inflammatory and innate immune response genes in the brain [8-10]. However, the molecular mechanisms underlying the neurovirulence of VEEV are not fully understood.

The host-virus interactions are generally reflected as specific changes in the gene-expression pattern and signal transduction pathways in the host [11]. Earlier, Grieder et al [3] have developed various site directed VEEV mutants that showed varying degree of neurovirulence [3]. These mutants can be used to study the differential pathogenesis of VEEV strains and may help in better understanding the neuropathology of VEEV. Therefore, in this study we evaluated the gene expression modulation in response to infection with a neurovirulent, V3000, and a partially neurovirulent, V3034, strains of VEEV. V3000 is a full length cDNA clone of the Trinidad Donkey (TrD) strain of VEEV. It is a neuroinvasive strain that is as neurovirulent and infectious as the wild type virus ( $\operatorname{TrD}$ strain) by peripheral, intracranial or aerosol inoculation [12]. V3034 is neuroinvasive but a partially lethal mutant of $\operatorname{TrD}$ strain with a single substitution (Threonine for Alanine) at El codon 272 , resulting in $11 \%$ mortality in mice infected either by peripheral or intracranial infection or $80 \%$ mortality via aerosol exposure [3]. In this study, we show that VEEV infection induced activation of germinal centers in the spleen. The severity of tissue pathology was markedly pronounced in V3000 infected mice as compared to V3034 infected mice. In the brain, inflammation was induced by both the viral strains and, similar to spleen, V3000 infection demonstrated increased and more widespread inflammation. Several genes were similarly modulated during infection with both the strains of VEEV suggesting that there may be a VEEV typical host response irrespective of the level of the virulence of the infecting strain. Several genes were differentially or uniquely modulated during infection with V3000 and V3034 infection suggesting induction of a viral strain-specific response from the host.

\section{Results \\ Neurovirulent and partially neurovirulent strains of VEEV induce markedly different pathological response in the spleen and brain. \\ VEEV infection in spleen}

The uninfected spleen displayed normal red and white pulp areas with some lymphoid aggregates in the white pulp containing few small germinal centers (Fig. 1m, n). A small mantle of mature lymphocytes was observed surrounding the germinal centers and occasional macrophages were present in the lymphoid aggregates; large multilobated megakaryocytes and extramedullary hematopoiesis was present predominantly beneath the capsule of the spleen.

At $24 \mathrm{~h}$ post infection (pi) significantly enlarged germinal centers were observed in V3000 infected mouse spleens. Germinal centers contained few neutrophils, but significantly increased numbers of macrophages, lymphocytes karryohrexis, apoptosis, and cellular debris (Fig. 1a, g). Similar changes were observed in the V3034 infected spleens; however, the extent of injury was markedly decreased at $24 \mathrm{~h}$ pi. (Fig. 1d, j). At $48 \mathrm{~h}$ pi, in V3000 infected mice, spleens displayed very active lymphoid aggregates containing markedly enlarged germinal centers. In case of V3034 infected mice spleens, far less germinal center activity was observed in comparison to V3000. Significantly decreased karyorrhexis and activity was evident in germinal center of V3034 infected spleens when compared to V3000 infection at $48 \mathrm{~h}$ pi (Fig. 1b, e, h, k). At $72 \mathrm{~h} \mathrm{pi}$, germinal centers were less active with V3000 infection in comparison to $48 \mathrm{~h}$ pi. A starry sky pattern was observed due to presence of numerous macrophages containing fragments of degenerating cells. Germinal centers in the white pulp appeared to be recovering their normal architecture (Fig. 1c, i). In comparison, spleens of V3034 infected mice at $72 \mathrm{~h}$ pi showed little starry sky pattern, inflammation and necrosis (Fig. 1f, l). Germinal center activity was very close to a normal tissue and germinal centers consisted primarily of normal appearing macrophages and lymphocytes. Interestingly, the amount of extra medullary hematopoiesis (EMH) in the subcapsular region of the spleen significantly decreased in the mice infected with V3000 over the progression of time with little to no hematopoiesis present at $72 \mathrm{~h}$ pi. However, in mice infected with V3034, the EMH 


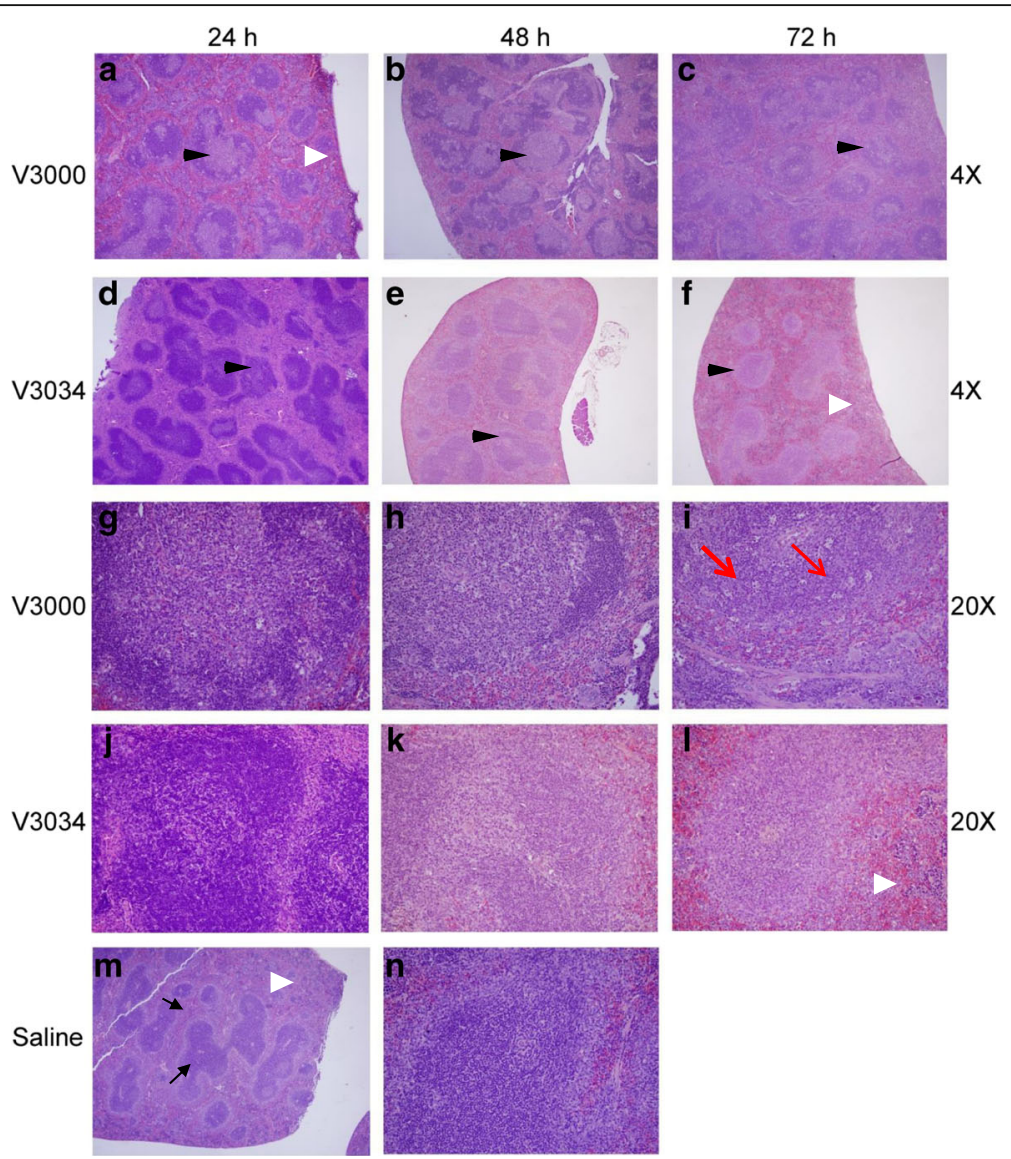

Fig. 1 Histology of the spleen following infection with V3000 or V3034 strains of VEEV. Spleen sections were analyzed by H\&E staining (a) V3000 at $24 \mathrm{~h}$ (4X), (b) V3000 at $48 \mathrm{~h}$ (4X), (c) V3000 at $72 \mathrm{~h} \mathrm{(4X),} \mathrm{(d)} \mathrm{V3034} \mathrm{at} 24 \mathrm{~h}(4 \mathrm{X}),(\mathbf{e})$ V3034 at $48 \mathrm{~h}(4 \mathrm{X}),(\mathbf{f})$ V3034 at $72 \mathrm{~h}(4 \mathrm{X}),(\mathbf{g})$ V3000 at $24 \mathrm{~h}(20 \mathrm{X}),(\mathbf{h})$ V3000 at $48 \mathrm{~h}$ (20X), (i) V3000 at $72 \mathrm{~h}$ (20X), (j) V3034 at $24 \mathrm{~h}$ (20X), (k) V3034 at $48 \mathrm{~h}$ (20X), (I) V3034 at $72 \mathrm{~h}$ (20X), (m) Saline (4X) and (n) Saline (20X). Spleens from salineinjected control animals showed normal red and white pulp area (thin arrows). Spleens from V3000 or V3034 infected mice exhibited germinal center activity (black arrow heads), which was more extensive in V3000 infected mice compared to V3034 infection. A starry sky pattern (indicated by red arrows) due to increased apoptosis was apparent with V3000 infection. EMH (white arrow head) was observed in V3034 infected spleens unlike V3000 at $72 \mathrm{~h}$

decreased at $48 \mathrm{~h}$ pi, but returned to almost normal at $72 \mathrm{~h}$ pi (Fig. 1d-f, j-1).

\section{VEEV infection in brain}

At $24 \mathrm{~h}$ pi, V3000 or V3034 infected mice brain looked similar to that of the uninfected controls with minimal inflammatory response. In case of V3000 infected mice, a mild increase in the cellularity was observed in the brains and progressive parencymal and perivascular inflammation as evidenced by focal mild endothelial cuffing, perivascular edema and parenchymal cellularity, which progressed from 48-72 h pi (Fig. 2a, c). V3034 infection resulted in decreased perivascular inflammation and cellularity as compared to V3000 at $48 \mathrm{~h}$ pi (Fig. 2b). At $72 \mathrm{~h} \mathrm{pi,} 3$ out of 4 mice brains infected with V3034 showed focal areas of mild inflammation throughout the brain as noted by the endothelial cuffing, edema around vessels, and escaping mononuclear cells in neocortex, striatum, thalamus, and hypothalamus regions of the brain (Fig. 2d). One of the remaining brains showed mild inflammation only in the neocortex region. An increase in inflammation was observed with V3000 infection at $96 \mathrm{~h}$ pi demonstrated by both the increase in number of vessels with perivascular cuffing and the degree of escaping mononuclear lymphocytes in comparison to $72 \mathrm{~h}$ pi (Fig. 2e). Similar increase in number of inflamed vessels was also observed in all animals infected with V3034 at $96 \mathrm{~h}$ pi however, the extent of inflammation was less than that seen in V3000 infection (Fig. 2f). Overall the extent of inflammation was more pronounced and widespread in brains of mice infected with V3000 as compared to those of the mice infected with V3034.

No VEEV specific immunohistochemical staining was observed in the brains of mice infected with either V3000 or V3034 at $24 \mathrm{~h}$ pi (Fig. 3a, b). At $48 \mathrm{~h}$ pi, VEEV staining could be seen in the olfactory lobe of the brains of mice infected with V3000 (Fig. 3c). However, no VEEV specific staining was observed in the brains of mice infected with 


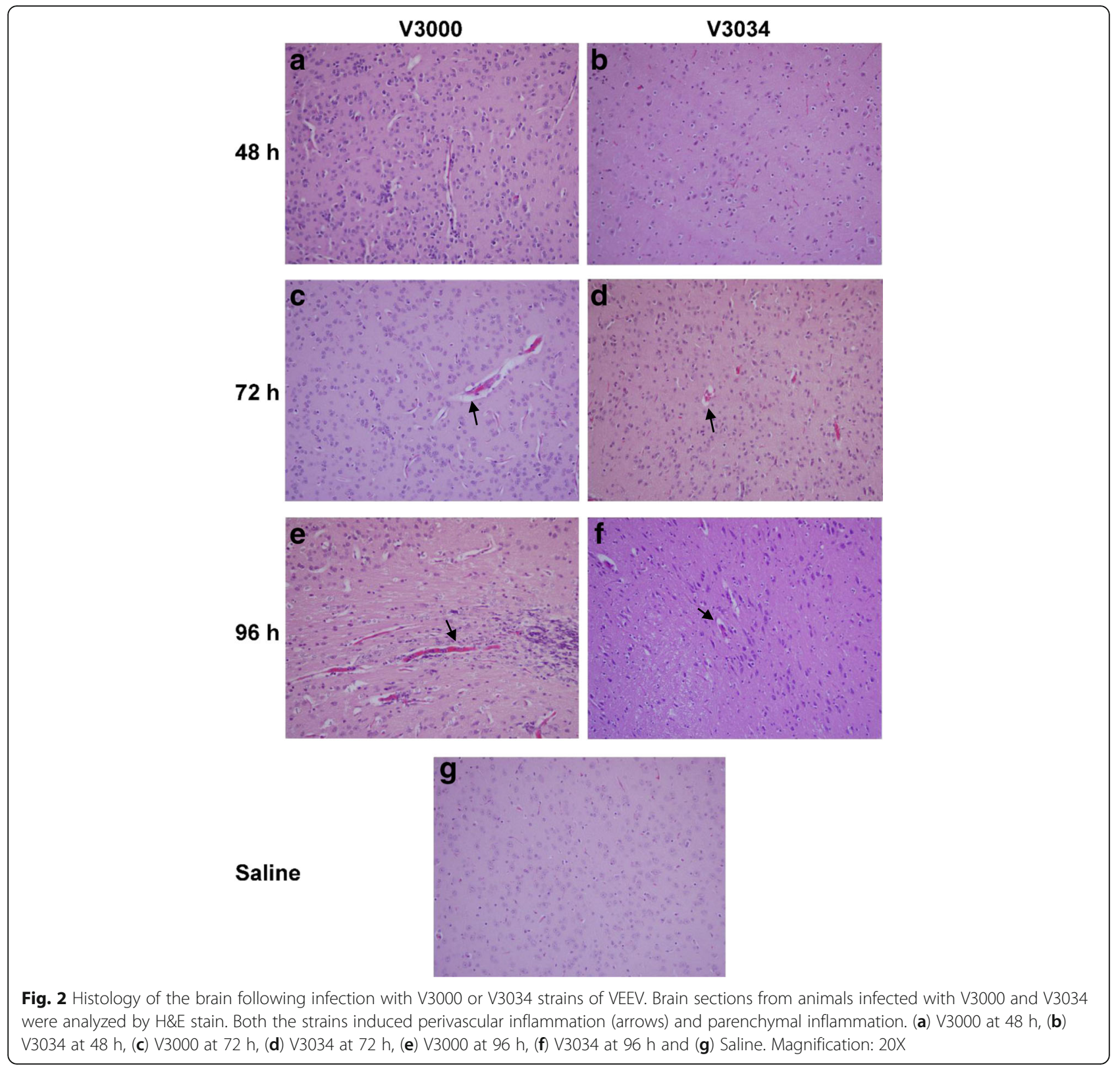

V3034 at this time point (Fig. 3d). By $72 \mathrm{~h} \mathrm{pi,} \mathrm{small} \mathrm{focal}$ VEEV staining was observed largely in neurons in the olfactory bulb, neocortex, striatum and hypothalamus region of the brain in all the animals infected with V3000 (Fig. 3e). Medulla, tegument and thalamus were generally negative for VEEV staining. In mice infected with V3034, 2 out of 3 brain samples were focally positive for VEEV staining at $72 \mathrm{~h}$ pi and VEEV staining was concentrated in the thalamus and hypothalamus regions of the brain (Fig. 3f). At $96 \mathrm{~h}$ pi, VEEV was significantly more widespread involving multiple regions of the brains of mice infected with V3000 (Fig. 3g). In contrast to the extensive staining of V3000 at $96 \mathrm{~h}$ pi, brain samples from V3034 infected mice showed only focal positive staining for
VEEV predominantly in the olfactory lobe of one mouse and thalamus region of another mouse (Fig. 3g-h). Overall VEEV staining was observed in both V3000 and V3034 infected brain sections, however, was more wide-spread and prominent in mice infected with V3000.

\section{VEEV strains induced differential host gene expression kinetics.}

VEEV induced gene expression in spleen

Lymphoid organs such as the lymph nodes and spleen are primary target sites of VEEV replication during the peripheral phase of infection. Both these strains have been shown to infect and replicate well in the spleen [3]. Therefore, to determine the host responses triggered during the 


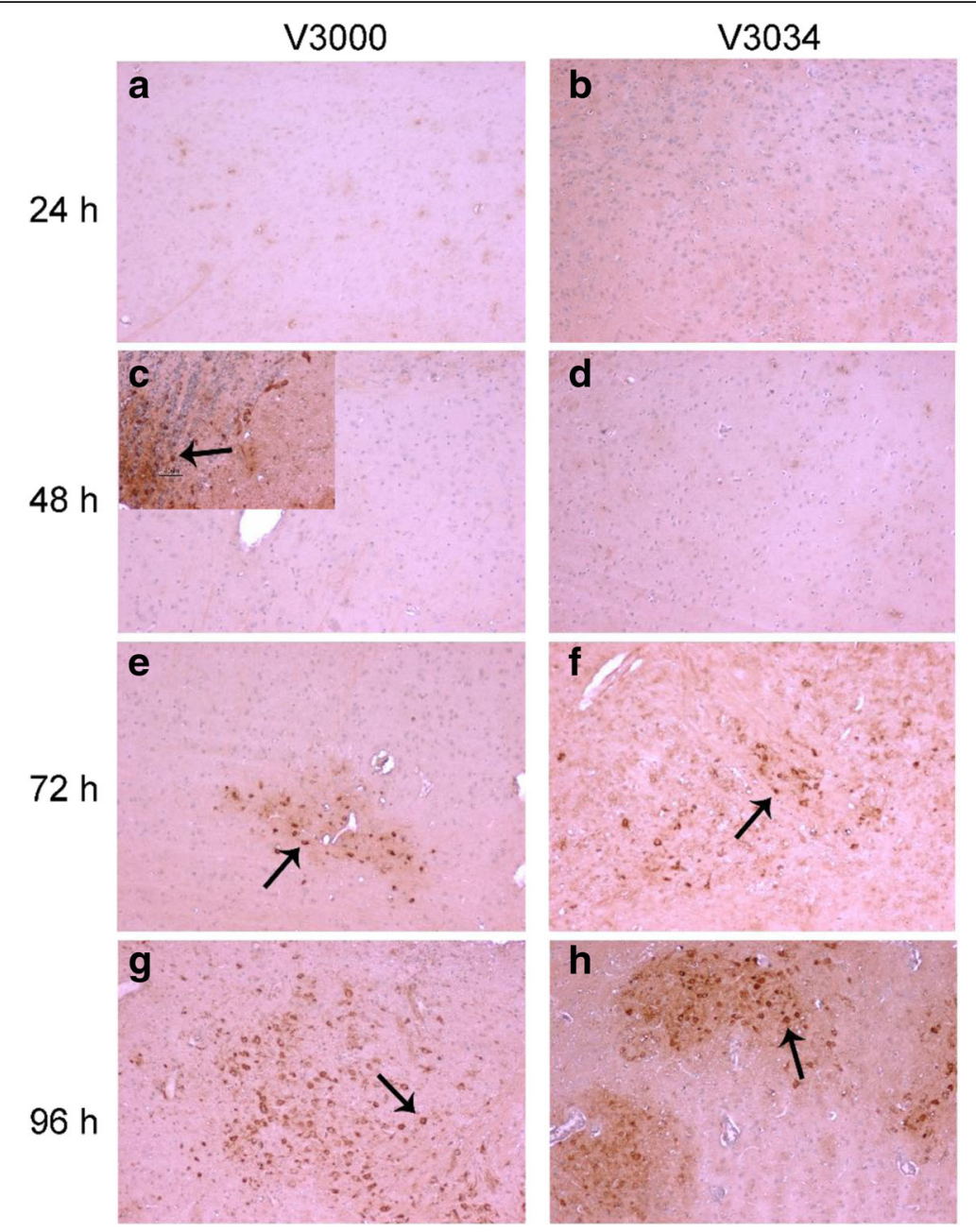

Fig. 3 Staining for VEEV antigen in the brain following infection with V3000 or V3034 strains of VEEV. Brain sections from animals infected with V3000 and V3034 were stained with VEEV-specific antibody to detect the presence of virus in the brain. (a) V3000 at 24 h, (b) V3034 at 24 h, (c) V3000 at 48 h, (d) V3034 at 48 h, (e) V3000 at 72 h, (f) V3034 at 72 h, (g) V3000 at 96 h and (h) V3034 at 96 h. At 48 h pi olfactory lobe (insert) showed positive staining for VEEV. Both the viruses showed positive VEEV staining (arrows) by $72 \mathrm{~h}$ pi. V3000 resulted in a more widespread staining in various regions of the brain which increased from $72 \mathrm{~h}$ to $96 \mathrm{~h}$ pi (hypothalamus shown here). In V3034 infected group at $96 \mathrm{~h}$ pi, one brain section showed VEEV staining only in the thalamus region (shown here) and one showed VEEV staining only in the olfactory lobe. Rest of the brain regions and sections were negative for VEEV staining after V3034 infection. Magnification: 20X

peripheral phase of infection by neurovirulent as well as partially neurovirulent strains of VEEV, we evaluated the gene expression profiles in the spleen during infection with V3000 and V3034 strains of VEEV at $24 \mathrm{~h}, 48 \mathrm{~h}$ and $72 \mathrm{~h}$ pi. V3000 infection resulted in significant modulation of 324, 531 and 486 gene transcripts in the spleen at $24 \mathrm{~h}$, $48 \mathrm{~h}$ and $72 \mathrm{~h} \mathrm{pi}$, respectively, compared to the uninfected controls (Table 1). V3034 infection resulted in significant modulation of 89,505 and 248 gene transcripts in the spleen at $24 \mathrm{~h}, 48 \mathrm{~h}$ and $72 \mathrm{~h}$ pi, respectively, compared to the uninfected controls (Table 1). Comparison of the different time points showed that 66 genes with V3000 infection and 16 genes with V3034 infection were similarly modulated at all the three time points (Additional file 1: Figure $\mathrm{S} 1 \mathrm{a}$ and $\mathrm{b}$ ). The number of significantly modulated genes increased at $48 \mathrm{~h}$ pi during infection with either of the viral strains, which was concomitant with the increased germinal center activity at $48 \mathrm{~h}$ pi for both the viruses.

\section{VEEV induced gene expression in brain}

The CNS phase of VEEV replication is characterized by active viral replication in neurons and glia cells in the brain. Therefore, to evaluate the host responses in the brain, gene expression kinetics was evaluated during infection with the neurovirulent (V3000) or the partially neurovirulent (V3034) strains of VEEV at $48 \mathrm{~h}, 72 \mathrm{~h}$, and $96 \mathrm{~h}$ pi. V3000 infection resulted in significant modulation of 241, 168 and 379 gene transcripts at $48 \mathrm{~h}, 72 \mathrm{~h}$ and $96 \mathrm{~h} \mathrm{pi}$, respectively (Table 1). V3034 infection resulted in significant modulation of 154, 206 and 224 gene transcripts in 
Table 1 Number of significantly modulated genes in spleen and brain

\begin{tabular}{|c|c|c|c|c|c|c|}
\hline & \multicolumn{3}{|l|}{ Spleen } & \multicolumn{3}{|l|}{ Brain } \\
\hline & $24 \mathrm{~h} \mathrm{pi}$ & $48 \mathrm{~h} \mathrm{pi}$ & $72 \mathrm{~h} \mathrm{pi}$ & $48 \mathrm{~h} \mathrm{pi}$ & $72 \mathrm{~h} \mathrm{pi}$ & $96 \mathrm{~h} \mathrm{pi}$ \\
\hline \multicolumn{7}{|l|}{ V3000 } \\
\hline Upregulated & 136 & 255 & 241 & 75 & 57 & 210 \\
\hline Downregulated & 188 & 276 & 245 & 166 & 111 & 169 \\
\hline Total & 324 & 531 & 486 & 241 & 168 & 379 \\
\hline \multicolumn{7}{|l|}{ V3034 } \\
\hline Upregulated & 58 & 252 & 210 & 62 & 79 & 71 \\
\hline Downregulated & 31 & 253 & 38 & 92 & 127 & 153 \\
\hline Total & 89 & 505 & 248 & 154 & 206 & 224 \\
\hline
\end{tabular}

Total RNA extracted from V3000 and V3034 infected spleen and brain was used to perform whole genome microarray as described in methods. Gene's modulated in all the replicates $(n=3), \geq 2.0$ fold (i.e., $\log _{2}$ ratio $\geq 1.0$ or $\leq-1.0$ ) relative expression level over uninfected controls, and $p$-value $\leq 0.05$ were considered significant

brain at $48 \mathrm{~h}, 72 \mathrm{~h}$ and $96 \mathrm{~h}$ pi, respectively (Table 1 ). Comparison of the different time points showed that 62 genes with V3000 infection and 70 genes with V3034 infection were similarly modulated at all the three time points (Additional file 1: Figure S1c and d).

\section{VEEV infection induced a subset of genes that was common} between both V3000 and V3034 strains.

To identify a host response to VEEV infection irrespective of the virulence of VEEV, the genes that were commonly modulated with both the neurovirulent as well as the partially neurovirulent strains of VEEV were identified. In the spleen, 32, 203 and 48 genes were found to be commonly modulated against both V3000 and V3034 infections at $24 \mathrm{~h}, 48 \mathrm{~h}$ and $72 \mathrm{~h}$ pi, respectively. All of the common modulated genes show a similar expression pattern for both the strains of VEEV, except for hemoglobin subunit beta-1 (Beta-s) gene, which showed downregulation with V3000 and upregulation with V3034 infections at $72 \mathrm{~h}$ pi. A complete list of genes commonly modulated against both the strains at different time points in the spleen is given in Additional file 2: Table S1. Four genes i.e., Fyb, Zbp1, I fi27l $2 a$ and Slc7a6os were commonly modulated in spleens of mice infected with either of the VEEV strains at all the three time points studied. In brain, 70, 83 and 121 genes were commonly modulated with both the VEEV strains at $48 \mathrm{~h}$, $72 \mathrm{~h}$ and $96 \mathrm{~h}$ pi respectively. All the genes displayed similar expression patterns, however, the extent of the modulation varied between infections with the two strains of VEEV. Of the commonly modulated genes, thirty two genes in the brain (such as Fyb, Mst1, Ilf3 and Socs3) were modulated at all the three time points studied. A complete list of genes commonly modulated against both the VEEV strains at different time points in the brain is given in Additional file 3: Table S2.

\section{VEEV infection induced subsets of genes that were unique to either the neurovirulent V3000 strain or the partially- neurovirulent V3034 strain}

To identify host responses specific to neurovirulent and partially-neurovirulent VEEV infection, genes that are uniquely modulated with V3000 or V3034 infection were identified. V3000 infection triggered significant modulation of 228, 204 and 316 unique genes at $24 \mathrm{~h}, 48 \mathrm{~h}$ and $72 \mathrm{~h}$ pi, respectively, in spleen. The 10 most upregulated genes for each time point are given in Table 2 . The remainder of the gene list, including the downregulated genes, is given in Additional file 4: Table S3. Of these, 11 genes (Socs1, Serpina3g, LOC100042025, Map4k4, Olfr819, Amfr, Vps37a, P2ry1, Slc12a5, Dtx3 and Trib2) were commonly modulated at all the three points studied in spleen. In the brain, 122, 59 and 99 genes were uniquely modulated at $48 \mathrm{~h}, 72 \mathrm{~h}$ and $96 \mathrm{~h}$ pi respectively, by V3000 infection. The 10 most upregulated genes for each time point are given in Table 3 . The remainder of the gene list, including the downregulated genes is given in Additional file 5: Table S4. Only histocompatibility 2, $\mathrm{T}$ region locus 23 (H2-T23) gene was found to be modulated at all the time points studied in the brain.

In the spleen, V3034 infection resulted in modulation of 46,198 and 172 unique genes at $24 \mathrm{~h}, 48 \mathrm{~h}$ and $72 \mathrm{~h}$ pi, respectively. The top 10 most upregulated genes for each time point are given in Table 4. The remainder of the gene list, including the downregulated genes, is given in Additional file 6: Table S5. In the brain, V3034 infection resulted in modulation of 55,89 and 51 genes unique genes at $48 \mathrm{~h}, 72 \mathrm{~h}$ and $96 \mathrm{~h} \mathrm{pi}$, respectively. The top 10 most upregulated genes for each time point are given in Table 5 . The remainder of the gene list, including the downregulated genes, is given in Additional file 7: Table S6. Only 3 genes each in the spleen (B2m, Lst1 and Edf1) and the brain (Six6, Cd163 and Bmp10) were modulated at all three time points after V3034 infection.

\section{Real time PCR validation.}

The microarray gene expression validation was completed by real time RT-PCR for randomly selected genes at different time points in the brain samples. Stat1, Stat2, $N f_{K} B 2$, $Z f p 456$ and $N t 5 c 2$ from the V3000-unique gene list, were shown to have similar expression pattern in both microarrays and real time PCR for the V3000 infected brain samples. In addition, Samd9l belonging to the VEEV specific subset, was found significantly up-regulated at $48 \mathrm{~h}$ pi in the V3000 and V3034 infected brain samples by both microarrays and real time PCR (Additional file 1: Figure S2 and Additional file 8: Table S7). 
Table 2 Significantly modulated genes in spleen unique to V3000

\begin{tabular}{|c|c|c|c|}
\hline UniGene & Gene & Description & $\log _{2} \operatorname{Exp} \pm$ SEM \\
\hline \multicolumn{4}{|c|}{ Genes uniquely modulated at $24 \mathrm{~h} \mathrm{pi}$} \\
\hline Mm.389688 & Oas1g & 2'-5' oligoadenylate synthetase $1 \mathrm{G}$ & $4.50 \pm 0.33$ \\
\hline Mm.218770 & Ifi202b & Interferon activated gene 202B & $4.42 \pm 0.41$ \\
\hline Mm.130 & Socs1 & Suppressor of cytokine signaling 1 & $4.26 \pm 0.40$ \\
\hline Mm.461583 & Zfp456 & Zinc finger protein 456 & $3.77 \pm 0.20$ \\
\hline Mm.271809 & Daxx & Fas death domain-associated protein & $3.77 \pm 0.16$ \\
\hline Mm.377095 & Ly6f & Lymphocyte antigen 6 complex, locus F & $3.62 \pm 0.26$ \\
\hline Mm.482110 & Ly6c2 & Lymphocyte antigen 6 complex, locus C2 & $3.56 \pm 0.18$ \\
\hline Mm.312628 & Serpina3g & Serine (or cysteine) peptidase inhibitor, clade A, member $3 G$ & $3.25 \pm 0.12$ \\
\hline Mm.20079 & Calml3 & Calmodulin-like 3 & $3.06 \pm 0.41$ \\
\hline Mm.261270 & Ifi204 & Interferon activated gene 204 & $2.83 \pm 0.06$ \\
\hline \multicolumn{4}{|c|}{ Genes uniquely modulated at $48 \mathrm{~h}$ pi } \\
\hline Mm.136573 & Stfa3 & Stefin A3 & $4.36 \pm 0.42$ \\
\hline Mm.766 & Cxcl9 & Chemokine (C-X-C motif) ligand 9 & $3.85 \pm 0.50$ \\
\hline Mm.390870 & BC117090 & CDNA sequence BC1179090 & $3.76 \pm 0.16$ \\
\hline Mm.8369 & Mst1 & Macrophage stimulating 1 & $3.65 \pm 0.34$ \\
\hline Mm.276739 & Sox 10 & SRY-box containing gene 10 & $3.42 \pm 0.25$ \\
\hline Mm.44176 & Efemp1 & $\begin{array}{l}\text { Epidermal growth factor-containing fibulin-like } \\
\text { extracellular matrix protein } 1\end{array}$ & $3.26 \pm 0.24$ \\
\hline Mm.338001 & Pld5 & Phospholipase D family, member 5 & $3.07 \pm 0.19$ \\
\hline Mm.272115 & Myom2 & Myomesin 2 & $3.03 \pm 0.17$ \\
\hline Mm.1583 & Ly6c1 & Lymphocyte antigen 6 complex, locus C1 & $2.92 \pm 0.09$ \\
\hline Mm.312628 & Serpina3g & Serine (or cysteine) peptidase inhibitor, clade A, member $3 G$ & $2.91 \pm 0.19$ \\
\hline \multicolumn{4}{|c|}{ Genes uniquely modulated at $72 \mathrm{~h}$ pi } \\
\hline Mm.40965 & $\mathrm{Nt} 5 \mathrm{c} 2$ & 5'-nucleotidase, cytosolic II & $3.61 \pm 0.16$ \\
\hline Mm.136573 & Stfa3 & Stefin A3 & $3.41 \pm 0.38$ \\
\hline Mm.312628 & Serpina3g & Serine (or cysteine) peptidase inhibitor, clade A, member $3 G$ & $3.11 \pm 0.32$ \\
\hline Mm.482110 & Ly6c2 & Lymphocyte antigen 6 complex, locus C2 & $3.10 \pm 0.19$ \\
\hline Mm.272115 & Myom2 & Myomesin 2 & $2.98 \pm 0.28$ \\
\hline Mm.20079 & Calml3 & Calmodulin-like 3 & $2.92 \pm 0.26$ \\
\hline Mm.359610 & Stfa2 & Stefin A2 & $2.86 \pm 0.38$ \\
\hline Mm.276389 & Hmox1 & Heme oxygenase (decycling) 1 & $2.47 \pm 0.25$ \\
\hline Mm.461583 & Zfp456 & Zinc finger protein 456 & $2.29 \pm 0.41$ \\
\hline Mm.34609 & Plac8 & Placenta-specific 8 & $2.28 \pm 0.09$ \\
\hline
\end{tabular}

Genes that were uniquely modulated against V3000 infection in the spleen were identified. The list summarizes 10 genes with maximum amount of upregulation for each time point. Values are expressed as average values of $\left(\log _{2}\right)$ fold expression for each gene over uninfected controls \pm standard error mean (SEM). ${ }^{*} P \leq 0.05$

\section{Signaling pathway analysis of genes modulated during VEEV infection \\ Pathway analysis of the genes uniquely expressed during infection with either V3000 or V3034}

Pathway analysis was performed on the genes uniquely modulated against V3000 and V3034 infection in the spleen and brain using the Ingenuity Pathway Analysis (IPA) software suit (Fig. 4). Antigen presentation and protein ubiquitination pathways were found to be commonly modulated by V3000 and V3034 infection in the spleen. The antigen presentation pathway was significantly modulated at all the time points by both virus infections. Protein ubiquitination pathway was significantly modulated at $24 \mathrm{~h}$ pi with V3000 infection and remained so for the remainder of the time points (Fig. 4a). In V3034 infection, the protein ubiquitination pathway was significantly modulated only at $48 \mathrm{~h}$ and $72 \mathrm{~h}$ pi (Fig. 4b). Some pathways were unique to 
Table 3 Significantly modulated genes in brain unique to V3000 infection

\begin{tabular}{|c|c|c|c|}
\hline UniGene & Gene & Description & $\log _{2} \operatorname{Exp} \pm$ SEM \\
\hline \multicolumn{4}{|c|}{ Genes uniquely modulated at $48 \mathrm{~h} \mathrm{pi}$} \\
\hline Mm.40965 & $\mathrm{Nt} 5 \mathrm{c} 2$ & 5'-nucleotidase, cytosolic II & $3.44 \pm 0.61$ \\
\hline Mm.461583 & Zfp456 & Zinc finger protein 456 & $2.79 \pm 0.56$ \\
\hline Mm.341423 & Dock4 & Dedicator of cytokinesis 4 & $2.16 \pm 0.05$ \\
\hline Mm.338001 & Pld5 & Phospholipase D family, member 5 & $1.90 \pm 0.21$ \\
\hline Mm.33902 & lgtp & Interferon gamma induced GTPase & $1.84 \pm 0.26$ \\
\hline Mm.211477 & Phldb2 & Pleckstrin homology-like domain, family B, member 2 & $1.76 \pm 0.13$ \\
\hline Mm.247453 & Abhd10 & Abhydrolase domain containing 10 & $1.50 \pm 0.22$ \\
\hline Mm.6856 & Pttg1 & Pituitary tumor-transforming gene 1 & $1.46 \pm 0.04$ \\
\hline Mm.290764 & Lrrc61 & Leucine rich repeat containing 61 & $1.43 \pm 0.26$ \\
\hline Mm.442861 & $\mathrm{H} 2-\mathrm{D} 4$ & Histocompatibility 2, D region locus 4 & $1.40 \pm 0.15$ \\
\hline \multicolumn{4}{|c|}{ Genes uniquely modulated at $72 \mathrm{~h} \mathrm{pi}$} \\
\hline Mm.141021 & Ifitm3 & Interferon induced transmembrane protein 3 & $2.98 \pm 0.37$ \\
\hline Mm.425949 & Ly6a & Lymphocyte antigen 6 complex, locus A & $2.64 \pm 0.46$ \\
\hline Mm.44176 & Efemp1 & $\begin{array}{l}\text { Epidermal growth factor-containing fibulin-like } \\
\text { extracellular matrix protein } 1\end{array}$ & $2.44 \pm 0.17$ \\
\hline Mm.439743 & $\mathrm{H} 2-\mathrm{Q} 7$ & Histocompatibility 2, Q region locus 7 & $2.35 \pm 0.13$ \\
\hline Mm.132226 & Ehd4 & EH-domain containing 4 & $2.05 \pm 0.30$ \\
\hline Mm.41075 & Drd4 & Dopamine receptor 4 & $1.97 \pm 0.15$ \\
\hline Mm.39825 & $\operatorname{Lm} \times 1 b$ & LIM homeobox transcription factor 1 beta & $1.84 \pm 0.12$ \\
\hline Mm.131422 & Osm & Oncostatin M & $1.67 \pm 0.26$ \\
\hline Mm.475107 & Rtp4 & Receptor transporter protein 4 & $1.51 \pm 0.10$ \\
\hline Mm.69751 & Pepd & Peptidase D & $1.44 \pm 0.11$ \\
\hline \multicolumn{4}{|c|}{ Genes uniquely modulated at $96 \mathrm{~h} \mathrm{pi}$} \\
\hline Mm.4950 & $\operatorname{lsg} 15$ & ISG15 ubiquitin-like modifier & $4.04 \pm 0.46$ \\
\hline Mm.425949 & Ly6a & Lymphocyte antigen 6 complex, locus A & $3.89 \pm 0.12$ \\
\hline Mm.284248 & Ccl5 & Chemokine ( $\mathrm{C}-\mathrm{C}$ motif) ligand 5 & $3.76 \pm 0.69$ \\
\hline Mm.290320 & $\mathrm{Ccl} 2$ & Chemokine ( $\mathrm{C}-\mathrm{C}$ motif) ligand 2 & $2.80 \pm 0.25$ \\
\hline Mm.24045 & Rsad2 & Radical S-adenosyl methionine domain containing 2 & $2.74 \pm 0.57$ \\
\hline Mm.133342 & Rnf213 & Ring finger protein 213 & $2.66 \pm 0.37$ \\
\hline Mm.24125 & Col4a3bp & Collagen, type IV, alpha 3 (Goodpasture antigen) binding protein & $2.59 \pm 0.43$ \\
\hline Mm.426537 & LOC 100041885 & PREDICTED: similar to C130026121Rik protein & $2.45 \pm 0.19$ \\
\hline Mm.439648 & $\mathrm{H} 2-\mathrm{T} 23$ & Histocompatibility 2, T region locus 23 & $2.32 \pm 0.44$ \\
\hline Mm.357727 & Gm46 & PREDICTED: gene model 46, (NCBI) & $2.31 \pm 0.23$ \\
\hline
\end{tabular}

Genes that were uniquely modulated against V3000 infection in the brain were identified. The list summarizes 10 genes with maximum amount of upregulation for each time point. Values are expressed as average values of $\left(\log _{2}\right)$ fold expression for each gene over uninfected controls \pm standard error mean (SEM).

${ }^{*} P \leq 0.05$

infection with each of the strains of VEEV. V3000 infection uniquely modulated several inflammatory signaling pathways such as IL-2, IL-4, IL-8, IL-9, IL-12 and IL-17A along with the unfolded protein response, gap junction signaling, crosstalk between DCs and NKCs, interferon and JAK/Stat signaling pathways (Fig. 4a). On the other hand, pathways such as virus entry via the endocytic pathway, or granzyme A signaling, dendritic cell maturation and complement system pathways were found to be significantly modulated only during V3034 infection (Fig. 4b).

In the brain, pathway analysis of uniquely modulated genes identified pathways such as, glioma, neuropathic pain, acute phase, JAK/Stat, Toll-like Receptor (TLR), chemokine and T-cell receptor (TCR) signaling pathways to be similarly modulated during infection with either of the VEEV strains (Fig. 5). Some of these pathways such as glioma, neuropathic pain, and acute phase response 
Table 4 Significantly modulated genes in spleen unique to V3034 infection

\begin{tabular}{|c|c|c|c|}
\hline UniGene & Gene & Description & $\log _{2} \operatorname{Exp} \pm \mathrm{SEM}$ \\
\hline \multicolumn{4}{|c|}{ Genes uniquely modulated at $24 \mathrm{~h} \mathrm{pi}$} \\
\hline Mm.276926 & Prss2 & Protease, serine, 2 & $5.61 \pm 0.83$ \\
\hline Mm.45316 & Cela2a & Chymotrypsin-like elastase family, member 2A & $5.17 \pm 0.20$ \\
\hline Mm.297477 & Cela3b & Chymotrypsin-like elastase family, member 3B & $5.10 \pm 0.29$ \\
\hline Mm.243758 & Apol9a & Apolipoprotein L 9a & $3.89 \pm 0.66$ \\
\hline Mm.4950 & $\operatorname{lsg} 15$ & ISG15 ubiquitin-like modifier & $3.47 \pm 0.38$ \\
\hline Mm.33902 & $\operatorname{lgtp}$ & Interferon gamma induced GTPase & $3.10 \pm 0.39$ \\
\hline Mm.23067 & Ufm1 & Ubiquitin-fold modifier 1 & $2.43 \pm 0.49$ \\
\hline Mm.32881 & Spnb1 & Spectrin beta 1 & $2.19 \pm 0.45$ \\
\hline Mm.439732 & $\mathrm{Clqc}$ & Complement component 1, q subcomponent, $\mathrm{C}$ chain & $1.91 \pm 0.32$ \\
\hline Mm.259916 & Chdh & Choline dehydrogenase & $1.86 \pm 0.08$ \\
\hline \multicolumn{4}{|c|}{ Genes uniquely modulated at $48 \mathrm{~h} \mathrm{pi}$} \\
\hline Mm.9714 & Gdf9 & Growth differentiation factor 9 & $4.80 \pm 1.03$ \\
\hline Mm.376121 & Olfr1152 & Olfactory receptor 1152 & $3.57 \pm 0.49$ \\
\hline Mm.132226 & Ehd4 & EH-domain containing 4 & $2.71 \pm 0.22$ \\
\hline Mm.386931 & Ecm2 & $\begin{array}{l}\text { Extracellular matrix protein 2, female organ } \\
\text { and adipocyte specific }\end{array}$ & $2.25 \pm 0.04$ \\
\hline Mm.302516 & Fsip2 & PREDICTED: fibrous sheath-interacting protein 2 & $2.19 \pm 0.34$ \\
\hline Mm.483584 & Serpina3f & Serine (or cysteine) peptidase inhibitor, clade A, member 3F & $2.08 \pm 0.20$ \\
\hline Mm.447 & Pyhin1 & Pyrin and HIN domain family, member 1 & $2.04 \pm 0.28$ \\
\hline Mm.265806 & Ankrd13c & Ankyrin repeat domain $13 \mathrm{c}$ & $1.89 \pm 0.12$ \\
\hline Mm.90450 & Myola & Myosin IA & $1.84 \pm 0.02$ \\
\hline Mm.41337 & Akr1c18 & Aldo-keto reductase family 1 , member C18 & $1.84 \pm 0.14$ \\
\hline \multicolumn{4}{|c|}{ Genes uniquely modulated at $72 \mathrm{~h} \mathrm{pi}$} \\
\hline Mm.297477 & Cela3b & Chymotrypsin-like elastase family, member 3B & $6.33 \pm 0.59$ \\
\hline Mm.45316 & Cela2a & Chymotrypsin-like elastase family, member 2A & $6.24 \pm 0.26$ \\
\hline Mm.485316 & Gm5409 & Predicted pseudogene 5409 & $6.11 \pm 0.50$ \\
\hline Mm.276926 & Prss2 & Protease, serine, 2 & $6.01 \pm 0.55$ \\
\hline Mm.8369 & Mst1 & Macrophage stimulating 1 & $5.87 \pm 0.50$ \\
\hline Mm.212333 & Pnliprp2 & Pancreatic lipase-related protein 2 & $5.59 \pm 0.66$ \\
\hline Mm.389688 & Oas1g & 2'-5' oligoadenylate synthetase $1 \mathrm{G}$ & $4.85 \pm 0.45$ \\
\hline Mm.245154 & Tmeff2 & $\begin{array}{l}\text { Transmembrane protein with EGF-like and two } \\
\text { follistatin-like domains } 2\end{array}$ & $4.32 \pm 0.45$ \\
\hline Mm.2745 & Ctrl & Chymotrypsin-like & $3.77 \pm 0.67$ \\
\hline Mm.243758 & Apol9a & Apolipoprotein L 9a & $3.27 \pm 0.23$ \\
\hline
\end{tabular}

Genes that were uniquely modulated against V3034 infection in the spleen were identified. The list summarizes 10 genes with maximum amount of upregulation for each time point. Values are expressed as average values of $\left(\log _{2}\right)$ fold expression for each gene over uninfected controls \pm standard error mean (SEM). * $P \leq 0.05$

signaling showed significant modulation at the same points in both viral strains. In contrast, pathways such as TCR, tumor necrosis factor receptor1 (TNFR1), and chemokine signaling showed differential kinetics in response to the infection with the two viral strains (Fig. 5a and b). Similar to the observations in spleen, several pathways were found to be significantly modulated during infection with only one of the VEEV strains in the brain as well. Pathways such as protein ubiquitination pathway, activation of interferon regulatory factors (IRFs) by cytosolic pattern recognition receptors (PRRs), CXC chemokine receptor4 (CXCR4) and $\mathrm{C}-\mathrm{C}$ motif Chemokine Receptor 5 (CCR5) signaling in macrophages were found to be significantly modulated only with V3000 infection (Fig. 5a). Pathways such as interferon, axonal guidance, synaptic long term potentiation, 
Table 5 Significantly modulated genes in brain unique to V3034 infection

\begin{tabular}{|c|c|c|c|}
\hline UniGene & Gene & Description & $\log _{2} \operatorname{Exp} \pm$ SEM \\
\hline \multicolumn{4}{|c|}{ Genes uniquely modulated at $48 \mathrm{~h} \mathrm{pi}$} \\
\hline Mm.40655 & Fam185a & Family with sequence similarity 185 , member $\mathrm{A}$ & $2.97 \pm 0.56$ \\
\hline Mm.57138 & Six6 & Sine oculis-related homeobox 6 homolog & $2.57 \pm 0.57$ \\
\hline Mm.141021 & Ifitm3 & Interferon induced transmembrane protein 3 & $2.54 \pm 0.31$ \\
\hline Mm.46418 & Chia & Chitinase, acidic & $2.34 \pm 0.38$ \\
\hline Mm.44176 & Efemp1 & $\begin{array}{l}\text { Epidermal growth factor-containing fibulin-like } \\
\text { extracellular matrix protein } 1\end{array}$ & $1.79 \pm 0.28$ \\
\hline Mm.103748 & Extl3 & Exostoses (multiple)-like 3 & $1.62 \pm 0.28$ \\
\hline Mm.207062 & Hoxc13 & Homeobox C13 & $1.59 \pm 0.28$ \\
\hline Mm.28162 & Nup210 & Nucleoporin 210 & $1.53 \pm 0.16$ \\
\hline Mm.41075 & Drd4 & Dopamine receptor D4 & $1.51 \pm 0.22$ \\
\hline Mm.42150 & Rasgrp1 & RAS guanyl releasing protein 1 & $1.44 \pm 0.31$ \\
\hline \multicolumn{4}{|c|}{ Genes uniquely modulated at $72 \mathrm{~h} \mathrm{pi}$} \\
\hline Mm.40965 & $\mathrm{Nt} 5 \mathrm{c} 2$ & 5'-nucleotidase, cytosolic II & $4.22 \pm 0.85$ \\
\hline Mm.461583 & Zfp456 & Zinc finger protein 456 & $3.18 \pm 0.52$ \\
\hline Mm.196581 & Mapk1 & Mitogen-activated protein kinase 1 & $2.75 \pm 0.29$ \\
\hline Mm.57138 & Six6 & Sine oculis-related homeobox 6 homolog & $2.70 \pm 0.37$ \\
\hline Mm.460823 & Gm10731 & Predicted gene 10,731 & $2.66 \pm 0.29$ \\
\hline Mm.357727 & Gm46 & PREDICTED: predicted gene 46 & $2.66 \pm 0.45$ \\
\hline Mm.364180 & 5033411D12Rik & RIKEN CDNA $5033411 \mathrm{D} 12$ gene & $2.54 \pm 0.37$ \\
\hline Mm.426537 & LOC100041885 & PREDICTED: sp110 nuclear body protein-like & $2.50 \pm 0.40$ \\
\hline Mm.245154 & Tmeff2 & $\begin{array}{l}\text { Transmembrane protein with EGF-like and two } \\
\text { follistatin-like domains } 2\end{array}$ & $2.13 \pm 0.30$ \\
\hline Mm.276739 & Sox10 & SRY-box containing gene 10 & $1.99 \pm 0.35$ \\
\hline \multicolumn{4}{|c|}{ Genes uniquely modulated at $96 \mathrm{~h} \mathrm{pi}$} \\
\hline Mm.57138 & Six6 & Sine oculis-related homeobox 6 homolog & $3.24 \pm 0.13$ \\
\hline Mm.196581 & Mapk1 & Mitogen-activated protein kinase 1 & $2.85 \pm 0.19$ \\
\hline Mm.196013 & Samd9| & Sterile alpha motif domain containing 9-like & $2.21 \pm 0.08$ \\
\hline Mm.41075 & Drd4 & Dopamine receptor D4 & $2.18 \pm 0.13$ \\
\hline Mm.32881 & Spnb1 & Spectrin beta 1 & $2.02 \pm 0.18$ \\
\hline Mm.323595 & Tob2 & Transducer of ERBB2, 2 & $1.76 \pm 0.19$ \\
\hline Mm.256414 & Slc9a2 & Solute carrier family 9 (sodium/hydrogen exchanger), member 2 & $1.64 \pm 0.13$ \\
\hline Mm.269029 & Slc7a6os & Solute carrier family 7, member 6 opposite strand & $1.61 \pm 0.24$ \\
\hline Mm.34428 & Pias4 & Protein inhibitor of activated STAT 4 & $1.38 \pm 0.02$ \\
\hline Mm.271745 & Nrp1 & Neuropilin 1 & $1.30 \pm 0.08$ \\
\hline
\end{tabular}

Genes that were uniquely modulated against V3034 infection in the brain were identified. The list summarizes 10 genes with maximum amount of upregulation for each time point. Values are expressed as average values of $\left(\log _{2}\right)$ fold expression for each gene over uninfected controls \pm standard error mean (SEM).

* $P \leq 0.05$

integrin, calcium, actin cytoskeleton and gap junction signaling were significantly modulated only with V3034 infection (Fig. 5b).

Network analysis of differentially modulated genes during infection with V3000 and V3034 strains

The molecule activity predictor (MAP) tool of IPA was used to generate gene networks overlaid with the relative gene expression values from the microarray data to identify differences in apoptosis, inflammation, and activation of immune cells against V3000 and V3034 infections. The software predicted overall activation or inhibition of various pathways based on the level of confidence by comparing gene expression values from the microarray data and the available published literature related to the gene interactions. Gene 


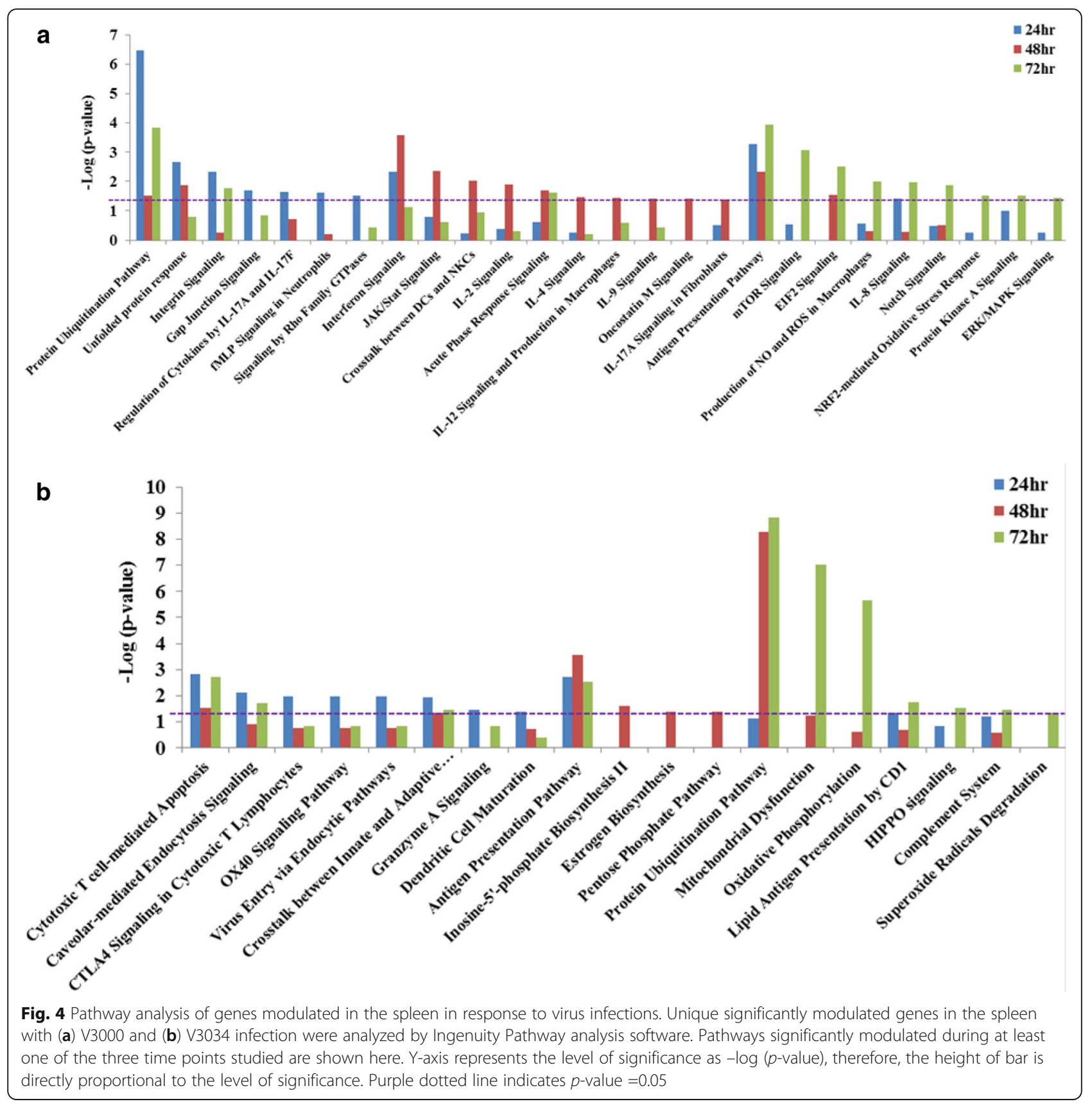

network analysis showed clear differences in the kinetics of apoptotic pathway in spleen with V3000 and V3034 infections. Various repressors of apoptosis such as Ilf3, Zmym2, Satb1, Ccl21 and Scd were downregulated and expression levels of inducers of apoptosis such as Daxx, Oas1, Lcn2 and Gng2 were upregulated with V3000 infection at $24 \mathrm{~h}$ pi resulting in an overall activation of the apoptotic pathway (Fig. 6). None of these genes were modulated by V3034 infection at $24 \mathrm{~h}$ pi. However, by $48 \mathrm{~h}$ and $72 \mathrm{~h}$ pi, the apoptotic network was predicted to be activated in spleen during infection with both the viral strains, however, the number of genes involved in apoptosis was less in V3034 as compared to V3000 at $72 \mathrm{~h}$ pi (Additional file 1: Figure S3). Inflammation represented by activation of various immune cells showed similar changes in the spleen. The spleen histology showed activation of macrophages in the germinal centers, which was more pronounced in case of V3000 infection as compared to the infection with V3034 at all the time points suggesting a difference in the kinetics of host response against infection by the two strains of VEEV. At $24 \mathrm{~h}$ pi, network analysis of genes that predict activation of phagocytes, macrophages, leukocytes, and antigen presenting cells 


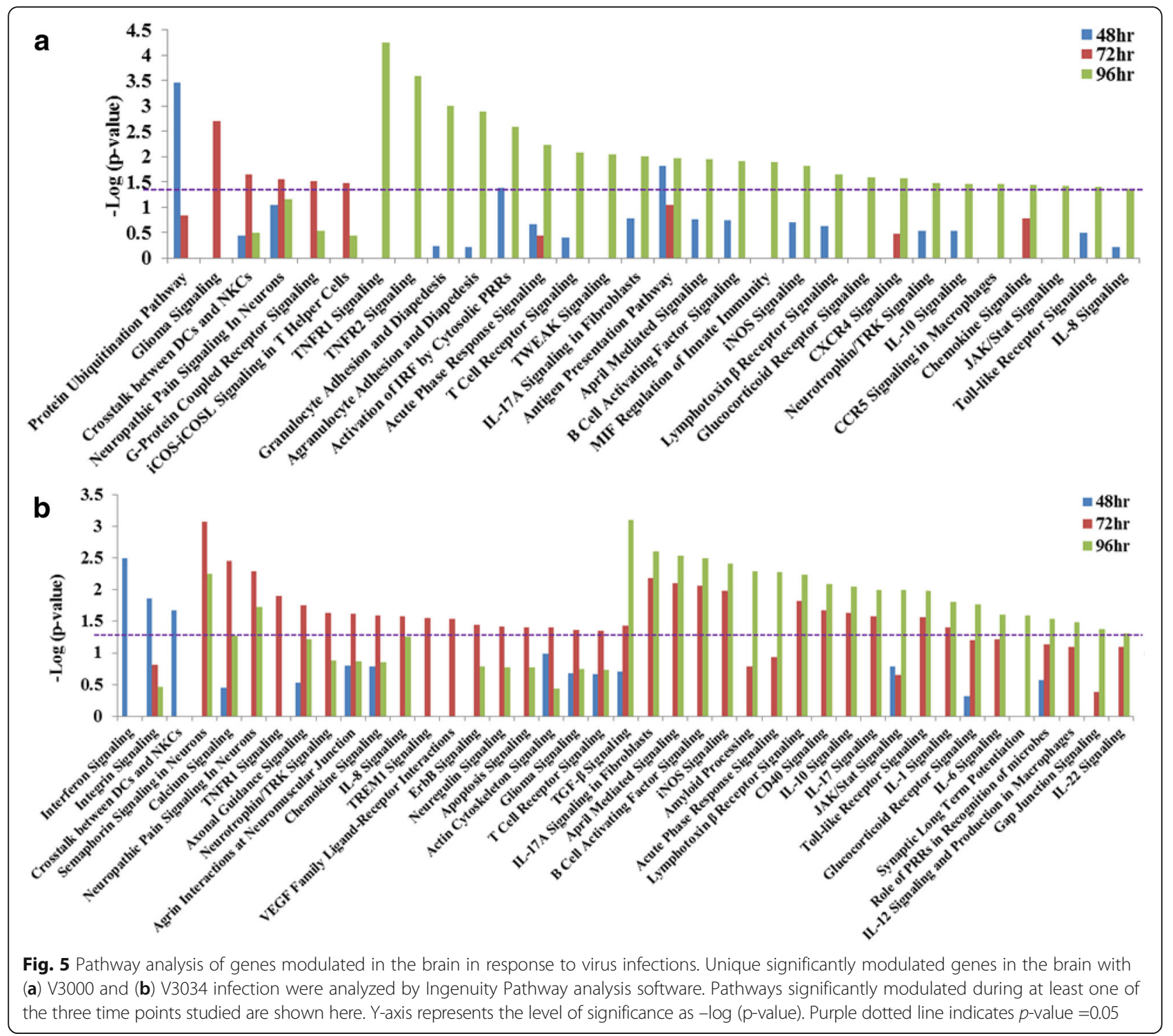

were upregulated after infection with V3000 (Fig. 7). For example, V3000 infection resulted in significant upregulation of $L c n 2$ gene (also known as $N G A L$ ) which is expressed in a variety of cells and tissues including neutrophils, and has been implicated in autoimmune diseases, infections, inflammation, musculoskeletal diseases, metabolic diseases and is being investigated in a clinical trial as a biomarker for acute kidney injury [13]. Upregulation of Lcn2 along with RhoA, Ccl5, Lgals3, $H s p D 1$ and Chil3/4 were predicted to activate myeloid and antigen presenting cells. In case of V3034 infection, these cells are not predicted to be activated due to lack of modulation in the expression of these genes at $24 \mathrm{~h}$ pi. Due to modulation of, $H L A-A$, only activation of leukocytes was predicted with V3034 infection. At $48 \mathrm{~h}$ and $72 \mathrm{~h}$ pi, both V3000 and V3034 infections resulted in activation of various immune cells due to modulation of a larger number of genes by both the viruses (Additional file 1: Figure S4).

Histological evaluation of the brain in our study demonstrated notable differences in inflammation and mononuclear cell infiltration into the brain as evident by perivascular cuffing (Fig. 8 inserts). Therefore, specific pathway analysis was done for inflammation and immune cell migration to identify genes that may play important roles in differential regulation of these pathways with infection of neurovirulent and partiallyneurovirulent strains of VEEV. A clear correlation of modulation of inflammatory pathways and the histology data was observed at $96 \mathrm{~h}$ pi. A greater numbers of genes were found to be modulated during infection with V3000 and accordingly inflammatory pathway and immune cell migration pathways were predicted to be significantly more affected during V3000 infection (Fig. 8a). 


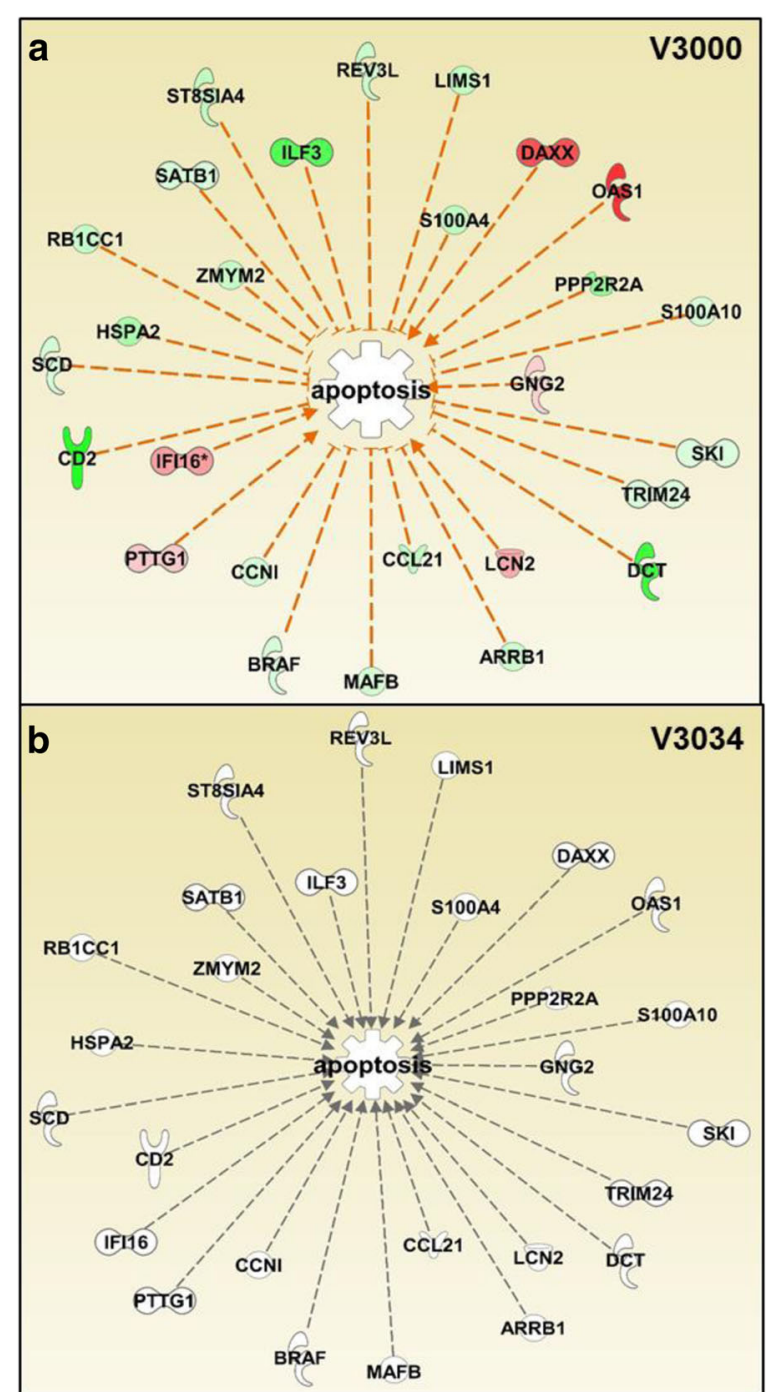

Fig. 6 Network analysis of apoptotic genes modulated in response to V3000 and V3034 infections in spleen at $24 \mathrm{~h}$ pi. In silico network analysis of significantly modulated genes in the spleen was performed for the apoptotic pathway using the Ingenuity Pathway analysis software. Analysis showed modulation of the apoptotic pathway in V3000 infection (a) mediated by upregulation of inducers and downregulation of repressors of apoptotic pathway. In the case of V3034 infection (b), such involvement of the apoptotic pathway was not observed. Legends: —: leads to activation, —: effect not predicted, $\bigcirc$ : upregulated, $\bigcirc$ : downregulated, $\bigcirc$ : not expressed; intensity of the color is directly proportional to the level of modulation

In comparison, during V3034 infection, only the neutrophil migration pathway was predicted to be significantly modulated, other pathways such as movement/recruitment of $\mathrm{T}$ lymphocytes, monocytes and granulocytes were not predicted to have any significant changes (Fig. 8b). This is in accordance with the reduced inflammatory response observed by histological staining in V3034 infected brain sections as compared to the V3000 infected brains.

\section{Discussion}

Lethal infection of VEEV results in neuronal cell death, increased cellularity, and an intense inflammatory response characterized by perivascular and interstitial mononuclear infiltrate in the brain, which ultimately results in death $[3,6,7,14-16]$. In the case of avirulent or partially virulent VEEV infections, the virus is generally cleared from the brain tissue with mild clinical symptoms and therefore, infection is usually not fatal [3]. Host factors that may play role in restricting VEEV replication during infection with avirulent or partially virulent strains are not well understood. Understanding of the molecular changes induced in the host upon VEEV infection resulting in either restriction or progression of viral replication and neurovirulence can identify potential host derived targets for drug development. Therefore, in this study, we compared host responses against 


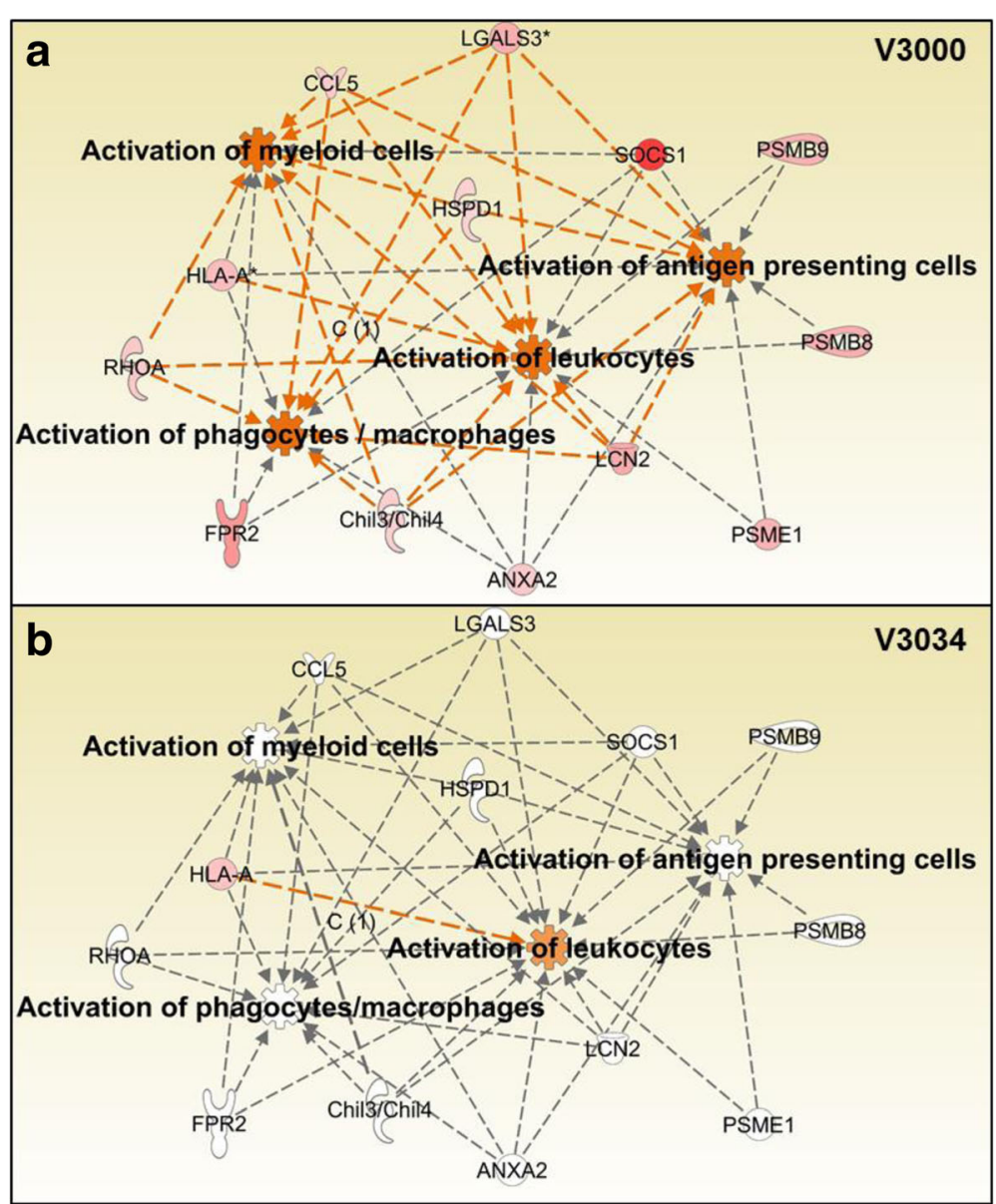

Fig. 7 Network analysis of inflammatory genes modulated in response to V3000 and V3034 infections in spleen. Genes significantly modulated against (a) V3000 and (b) V3034 infection in the spleen were used to perform in silico network analysis using the Ingenuity Pathway analysis software. V3000 infection resulted in increased inflammation by upregulating the genes associated with activation of myeloid cells, antigen presenting cells, phagocytes/macrophages and leukocytes unlike V3034, which only resulted in activation of leukocytes at $24 \mathrm{~h}$ pi. Legends:leads to activation, $\longrightarrow$ : effect not predicted, $\bigcirc$ : upregulated, $\bigcirc$ : downregulated, $\bigcirc$ : not expressed; intensity of the color is directly proportional to the level of modulation

two VEEV strains, V3000 and V3034 that reach the host brain, but show difference in neuropathology and lethality.

V3000 and V3034 have been shown to replicate in the spleen of mice [3]. In this study we found that the extent of spleen pathology was markedly different in between the two strains. V3000 infection induced a higher degree of germinal center activation that peaked at $48 \mathrm{~h}$ pi. V3034 infection also followed this pattern, however, degree of germinal center activation was significantly less at each time point in comparison with V3000 infection. These observations correlate with the increased number of genes significantly modulated in the spleen with VEEV infection at the three time points. Pathway and network analyses identified a stronger apoptotic and inflammatory response with V3000 infection at $24 \mathrm{~h}$ pi as compared to V3034 infection which was similar to the observed histologic changes in these tissues. Both strains induced a similar pattern of modulation among common genes except for that of Beta-s, which was downregulated during V3000 infection but upregulated during V3034 infection. Beta-s also known as $\mathrm{Hbb}$ encodes for beta-globulin that form part of the hemoglobin complex in red blood cells. Interestingly, increase in Beta-s expression corresponds with the increased EMH in the spleen of V3034 infected mice at $72 \mathrm{~h}$ pi. More detailed study will be needed to establish direct role of Beta-s in promoting $\mathrm{EMH}$ in the spleen during VEEV infection. Genes such as Ifi27l2a, which regulate immune cell influx [17], and Ifitm3, which has antiviral function [18], were upregulated in both V3000 and V3034 infection suggesting there role in antiviral response during infection with VEEV. Ifitm3 has been reported to be upregulated in spleen during VEEV-TrD infection in macaques [19] and has been shown to play a critical role in protection against several viral infections $[18,20,21]$. Taken 

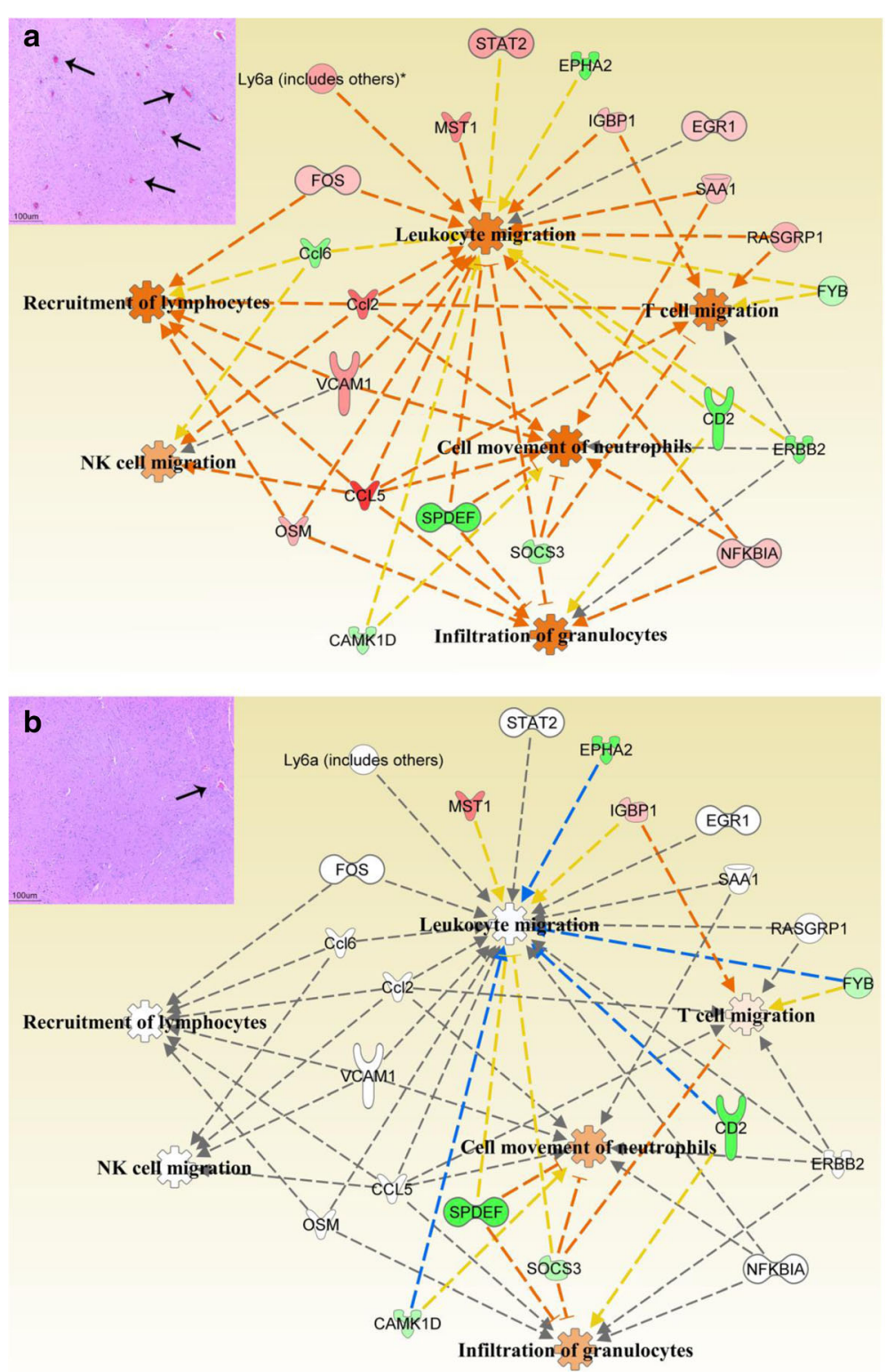

Fig. 8 Network analysis of inflammatory genes modulated in response to V3000 and V3034 infections in brain. Genes significantly modulated against (a) V3000 and (b) V3034 infection in brain at $96 \mathrm{~h}$ pi were used to perform in silico network analysis using the Ingenuity Pathway analysis software. V3000 infection resulted in enhanced inflammation by significantly upregulating the genes causing leukocyte migration, T cell migration, recruitment of lymphocytes, NK cell migration, infiltration of granulocytes and neutrophil movement. V3034, on the other hand, only resulted in enhanced infiltration of granulocytes and neutrophil cell movement to some extent. Legends: —: leads to activation, —: leads to inhibition, $\longrightarrow$ : finding inconsistent with the state of downstream molecule, 2 : effect not predicted, $\bigcirc$ : upregulated, $\bigcirc$ : downregulated, : not expressed; intensity of the color is directly proportional to the level of modulation

together, these observations indicate that although both the strains trigger host-mediated defense responses which probably help in clearance of the virus from spleen, the highly virulent V3000 strain induced a stronger inflammatory response which may result in the more extensive pathology identified in the spleen tissue as compared to the less virulent V3034 strain.
Neurovirulence is the hallmark of lethal VEEV infection. Replication of VEEV in the neurons and glia, and associated inflammatory response leads to extensive encephalitis and death of animals [3, 6, 7, 14-16]. Both V3000 and V3034 have been shown to enter the CNS. V3000 causes extensive neuronal death and inflammation of CNS leading to $100 \%$ mortality in mice, whereas 
V3034 only causes death in $11 \%$ of the infected mice [3]. Several host genes were commonly modulated against the neurovirulent as well as partially-neurovirulent strain of VEEV. Genes like B2m, Mst1, Igsf1, Ifitm3 and Nt5c2 were found to be upregulated whereas genes like $F y b$, Ilf3, Wnt4 and Socs3 were found to be downregulated in the brain against both V3000 and V3034 infections. Mst1, a serine/threonine kinase activated by caspases during apoptosis, has been shown to be critical to influenza A virus replication [22]. Mst1 has also been shown to prevent autophagy and facilitates neurodegeneration during amyotrophic lateral sclerosis [23, 24]. Mst1 was upregulated in spleen during V3000 and V3034 infection and therefore, likely may contribute positively towards VEEV replication in the brain and spleen. Ifitm3 is an antiviral protein that has been shown to induce innate immune response against influenza $\mathrm{A}$, West nile, rift valley fever, dengue and vesicular stomatitis viruses $[18,20$, 25 , 26]. Ifitm3 was also upregulated in spleen and brains of both V3000 and V3034 infected mice. Socs3 expression has been shown to reduce the virus replication, and in this study its downregulation in both V3000 and V3034 infected mice brain and spleen suggests that VEEV may inhibit Socs3 expression for its own replication, which is also reflected in the brain histology that shows active replication of V3000 and V3034 in the brains of infected mice [27, 28]. We have previously shown that VEEV infection increases the expression of $B 2 m$ and $H 2 Q 7$, which are involved in the antigen presentation pathway [8]. In this study, $B 2 m, H 2 Q 7$ and H2Q6 expression was upregulated by both the viral strains suggesting a common innate immune response to both the viral strains. Pathway analyses also identified activation of several innate immune pathways such as crosstalk between DCs and NKCs, T cell receptor, acute phase response, chemokine, JAK/stat and TLR signaling pathways against both the virulent and partially-virulent VEEV strains suggesting these to be common immune responses to VEEV infection, although the kinetics of their modulation varied with the strain of VEEV. Surprisingly, V3034 resulted in modulation of a larger number of host signaling pathways at $72 \mathrm{~h}$ pi. This probably suggests a much stronger host response during a partially virulent VEEV infection, which may help in controlling the virus infection during the later time points.

Activation of inflammatory cells is critical to virus clearance however; and the excessive inflammation in the brain caused by VEEV has been implicated in neurodegeneration $[6,7,9,12]$. Several chemokines $C c l 2, C c l 5$ and $\mathrm{Ccl} 6$, and genes from the lymphocyte antigen 6 superfamily, $L y 6 a$, Ly6e and $L y 6 f$ were found to be modulated only with V3000 infection in brain. This correlates with the higher degree and more extensive inflammation that was observed in the brains of V3000 infected mice.
We have earlier reported the upregulation of $\mathrm{Ccl} 2$ in the brains of mice infected with V3000 [10]. Ccl2 which is also known as monocyte chemoattractant protein-1 (MCP-1) has also been implicated in encephalitis caused by viruses including VEEV, and has been shown to play role in permeability of blood brain barrier and leukocyte migration into the brain parenchyma [29-33]. Ccl6 is expressed by the microglia and regulates their migration in the normal brain [34]. Ccl6 expression is also increased in the CNS during inflammatory demyelinating diseases and it acts as a chemoattractant for leukocytes [35]. In addition, Ccl6 has been implicated in encephalitis induced by West Nile virus [36]. Lymphocyte antigen 6 (Ly6) gene encodes for lycosyl-phosphatidyl-inositol anchored cell-surface proteins [37]. Function of Ly6 superfamily of genes have not been completely defined, however, some of these genes have been implicated in various immune response functions such as T-cell homing and activation, and regulation of the complement attack complex [38, 39]. More specifically, $L y 6 a$, also known as Stem cell antigen-1 (Sca-1) or T-cell activating protein $(T A P)$, is expressed on hematopoietic stem cells and has been shown to be involved in T-cell development and cell-cell adhesion [40, 41]. Ly6e, also known as Sca-2 or Thymic Shared Antigen-1 (TSA-1 ), has been identified as a biomarker for systemic lupus erythematosus and shown to be involved in cell-cell adhesion, as well as B-cell and T-cell regulation [42-45]. Ly6 genes were preferentially upregulated in V3000 infected brains (as well as spleens), and may play a role in microvascular inflammation and mononuclear cell migration in the brain which was markedly increased during V3000 infection as compared to the V3034 infection. Significant upregulation of VCAM-1 was also observed in V3000 infected mice brain, but not in V3034 infected mice brain. VCAM-1 is a regulator of T-cell mediated inflammatory response and has been shown to contribute adversely towards immunopathology during viral infections [46]. Earlier, we have shown an increased expression of VCAM-1 in VEEV infected mouse brain [9]. Although V3000 and V3034 both demonstrated inflamed vessels in the brain, gene network analysis found a much stronger activation of inflammatory response such as recruitment of lymphocytes, infiltration of granulocytes, movement of neutrophils and migration of leukocytes, NK cells and T-cells with V3000 infection as compared to V3034 infection in the mouse brain. Other studies have also demonstrated that infiltration of $\mathrm{T}$ cells and a strong NK cell response in the brain is associated with lethal alphavirus infections $[47,48]$. Selective upregulation of the chemokines and adhesion molecules in V3000 infected mouse brains thereby, may be responsible for the higher degree of inflammation that was observed in V3000 infected brain as compared to the 
V3034 infected brain, and genes such as Ccl2, Ccl6, Ly6 and $V C A M-1$ may play role in adverse outcome of VEEV replication in brain.

\section{Conclusion}

In conclusion, comparative analysis of gene expression from the spleen and brain of mice infected with highly neurovirulent V3000 or partially neurovirulent V3034 strains of VEEV identified several host factors that support the increased inflammatory reaction, spleen pathology and lethal encephalitis following V3000 infection. One of the limitations of this study is that the differences in the number of significantly modulated genes and their expression levels could be affected by the level of virus replication in the tissue. At the same time, the decreased pathology observed in the tissue of mice infected with less pathogenic virus could be a reflection of better control and repair by the host response against the virus replication. The goal of present study was to evaluate the molecular responses in the host tissues that are primarily targeted by VEEV. Overall responses discussed in this study are representative of the combined response of various cell types present in the lymphoid tissue (spleen) and the brain. Further studies will be needed to identify responses of individual cell types against the different strains of VEEV and the role of individual genes in supporting or controlling the VEEV infection and disease.

\section{Methods}

\section{Virus strains and animals}

Virus stocks used in this study were acquired from Dr. Franziska B. Grieder, USUHS, Bethesda, MD. Two different strains of VEEV were used: V3000 and V3034. Six-ten weeks old male CD-1 mice ( $\mathrm{n}=3$ per group, 10$12 \mathrm{~g}$, purchased from Jackson Laboratory, Bar Harbor, ME) were used for the studies. Mice were given mild anesthesia using isoflurane and $1000 \mathrm{pfu}$ of either of the 2 strains of VEEV in $25 \mu \mathrm{l}$ volume was inoculated in the left rear footpad using sterile 26G(3/8) intradermal bevel needle on $1 \mathrm{~cm}^{3}$ sterile syringe (Becton Dickinson and Company, Franklin Lakes, NJ). Footpad inoculation was chosen as it closely mimics the natural route of VEEV infection via mosquito bite. Working dilutions of virus were made by diluting stock virus solution in $1 \mathrm{X}$ Dulbecco's phosphate buffered saline (DPBS) (Gibco, Invitrogen Corporation, Carlsbad, CA). Control mice were inoculated with $25 \mu \mathrm{l}$ of sterile $1 \mathrm{X}$ DPBS in left rear footpad. Spleen samples were collected at $24 \mathrm{~h}, 48 \mathrm{~h}$ and $72 \mathrm{~h}$ pi and brain samples were collected at $48 \mathrm{~h}, 72 \mathrm{~h}$ and $96 \mathrm{~h}$ pi and were immediately stored in trizol at $-80{ }^{\circ} \mathrm{C}$ for RNA extraction or in formalin at room temperature for histological evaluation. The experiments with virulent VEEV were conducted in the BSL3 facility at USUHS during the time period when USUHS was registered with the $\mathrm{CDC}$ select agent program. All the animal handling and euthanasia protocols were reviewed and approved by the Institutional Animal Care and Use Committees.

\section{Total RNA isolation}

Total RNA from spleen was collected at $24 \mathrm{~h}, 48 \mathrm{~h}$ and $72 \mathrm{~h}$ pi and from brain was collected at $48 \mathrm{~h}, 72 \mathrm{~h}$ and $96 \mathrm{~h}$ pi using TriZol method (Invitrogen Inc., Carlsbad, $\mathrm{CA}$ ) according to the manufacturers' protocols. Briefly, the tissue was minced in TriZol reagent ( $1 \mathrm{X}$ volume) and mixed with chloroform ( $0.2 \mathrm{X}$ volume). After $5 \mathrm{~min}$ of incubation, the aqueous and organic phases were separated by centrifugation at $11,000 \mathrm{rpm}$ for $15 \mathrm{~min}$ at $4{ }^{\circ} \mathrm{C}$. The aqueous phase was collected and mixed with isopropanol (0.5X volume) followed by centrifugation at $11,000 \mathrm{rpm}$ for $10 \mathrm{~min}$ at $4 \mathrm{C}$. The pellet was washed with $1 \mathrm{ml} \mathrm{70 \%} \mathrm{ethanol} \mathrm{and} \mathrm{centrifuged} \mathrm{at} 9500 \mathrm{rpm}$ for $5 \mathrm{~min}$ twice. RNA pellet was then air dried and dissolved in nuclease free water. The total RNA isolated was then purified using the RNeasy mini kit (Qiagen Inc.) to remove any contamination. Briefly, $100 \mu \mathrm{l}$ RNA sample was mixed with $350 \mu \mathrm{l}$ RLT buffer and $250 \mu \mathrm{l} 100 \%$ ethanol. After vigorous mixing, it was filtered through the filter cartridge provided with the kit at $10,000 \mathrm{rpm}$ for $30 \mathrm{~s}$. Filter cartridge was washed twice by loading $500 \mu \mathrm{RPE}$ buffer and centrifugation at $10,000 \mathrm{rpm}$ for $30 \mathrm{~s}$. Filter cartridge was transferred onto a fresh tube and spin dried at 10,000 rpm for $1 \mathrm{~min}$. RNA was then eluted in 30-50 $\mu \mathrm{l}$ nuclease free water. Purified RNA was quantified spectrophotometrically using Beckman DU640 spectrophotometer (Beckman Instruments Inc., Columbia, MD) and stored at $-80{ }^{\circ} \mathrm{C}$. RNA quality was determined by running it on $1 \%$ denaturing formaldehyde agarose gel.

\section{Microarray experiment}

The high quality mouse microarrays containing oligonucleotides were produced in the laboratory at CBER/FDA. These arrays contain 35,852 oligonucleotide (70-mer) probes, representing approximately 25,000 unique genes and 38,000 transcripts, and additional 380 oligonucleotides as positive, negative and spike-in controls. The oligo set (version 4.0) used for these arrays was purchased from Operon Molecules for Life, Inc. The design of probes was based on the Ensembl Mouse Database release 26.33b.1, Mouse Genome Sequencing Project, NCBI RefSeq, Riken full-length cDNA clone sequences and other GenBank sequences. The detailed information regarding array printing, post-printing processing, and testing array quality is described elsewhere [49].

The total RNA isolated from brain and spleen samples was used for microarray hybridization and labeling using 3DNA Array 900 expression array detection kit from Genisphere Inc. as described by the manufacturer. Briefly, cDNA was synthesized from $1.5 \mu \mathrm{g}$ of total RNA 
at $42{ }^{\circ} \mathrm{C}$ using SS-II reverse transcription enzyme and RT primers specific to cy5/cy3 dye dendrimers (Genisphere Inc.). The cDNAs were first hybridized with microarray slides overnight at $42{ }^{\circ} \mathrm{C}$ in MAUI microarray hybridization chambers (Biomicro systems Inc.) followed by stringent washes. Slides hybridized with cDNA were then end labeled with $\mathrm{Cy} 5 / \mathrm{Cy} 3$ dyes containing dendrimers at $65^{\circ} \mathrm{C}$ for $5 \mathrm{~h}$ in MAUI microarray hybridization chambers followed by stringent washes. The slides were scanned using the Axon GenePix 4000B scanner with a $10-\mu \mathrm{m}$ resolution.

\section{Microarray data analysis}

Microarray slides were scanned on an Axon GenePix 4000B scanner (Axon Instruments, Inc., Foster City, CA) with a $10-\mu \mathrm{m}$ resolution. The raw data files were generated from scanned microarray images using GenePix Pro 5.1 software were imported into mAdb (microarray database), and analyzed by the software tools in the mAdb database provided by Center for Information Technology (CIT), National Institutes of Health (NIH) as described before [8]. The advanced filters were applied before data analysis to select only the spots with spot size of $10 \mu \mathrm{m}$ to $300 \mu \mathrm{m}$, $\leq 80 \%$ signal saturation, minimum fluorescent intensity of 150 and signal $\geq 2 \mathrm{SD}$ (standard deviation) above background in both Cy3 and Cy5 channels. Global normalization was performed utilizing the Loess normalization method. All the biological replicates ( $\mathrm{n}=3$ at each time point) shared significant homology in gene expression pattern with correlation coefficients of $\geq 0.80$ and clustered together in hierarchical clustering analysis. The genes with $\geq 2.0$ fold relative expression $\left(\log _{2}\right.$ ratio $\geq 1.0$ or $\leq-1.0$ ) over the uninfected controls in all the three biological replicates and with $p$-value $\leq 0.05$ were considered significantly modulated. Further analysis was performed using software tools in the Ingenuity Pathway Analysis (IPA) Software suit (https://www. qiagenbioinformatics.com/products/ingenuity-pathwayanalysis/) to identify biological functions and relevant pathways representing these genes. Gene networks were also generated using the web-based tools from IPA.

\section{Histology}

Spleen and brain samples collected at various time points pi were immediately fixed in $10 \%$ phosphate buffered formalin for 3-4 weeks. Paraffin embedded tissue was sectioned at $5 \mu \mathrm{m}$ thickness and stained with haematoxylin and eosin (H \& E) for histopathological analysis. For detecting the presence of virus, tissue sections were incubated with anti-VEEV antibody (rabbit polyclonal antiserum $(1: 10,000)$, raised against VEEV, eastern equine encephalitis virus, western equine encephalitis virus and sindbis virus; kindly provided by Dr. Cindy Rossi and Dr. George Ludwig, United States Army Medical
Research Institute for Infectious Diseases, Frederick, MD) as previously described [8]. An indirect avidin-biotinimmunoperoxidase technique was used for IHC using Vectastain ABC Elite kit (Vector Laboratories) and sections were counter-stained with haematoxylin QS (Vector Laboratories) as specified by the manufacturer. Stained slides were examined under the microscope (Nikon Eclipse E400, Nikon, Instruments Inc., Melville, NY).

\section{Quantitative Real Time PCR}

Expression level of selected genes from the microarray results was validated through quantitative real-time PCR. SuperScript- III First-Strand Synthesis System was used to prepare cDNA from amplified RNA samples and SYBR Green PCR master mix (Applied biosystems Inc.) was used to perform PCR. Reactions were run on $7900 \mathrm{HT}$ fast real time PCR machine using the following cycle: $95{ }^{\circ} \mathrm{C}$ for $10 \mathrm{~min}$, followed by 40 cycles at $95^{\circ} \mathrm{C}$ for $15 \mathrm{~s}$ and $60^{\circ} \mathrm{C}$ for $1 \mathrm{~min}$. The details of the primer sets used are given in Additional file 8: Table S7. The data obtained was analyzed with ABI RQ manager software (Carlsbad, CA) by the $2^{-\Delta \Delta C t}$ method and normalized against housekeeping gene, GAPDH. Data is representative of at least 2 technical replicate for each biological replicate.

\section{Statistical analysis}

All the results are expressed as mean $\log _{2}$ fold expression \pm SEM ( $\mathrm{N}=3$ per group). Student's t- test was used for comparison of groups. For all data, statistical significance was accepted at $p \leq 0.05$.

\section{Additional files}

Additional file 1: Figure S1. Venn diagram with comparison of gene expression at different time points in a) V3000 infected spleen, b) V3034 infected spleen, c) V3000 infected brain, and d) V3034 infected brain. Significantly modulated genes against each virus at different time points studied were compared in spleen and brain. The genes representing unique or common subsets are shown in the venn diagrams. The numbers in the venn diagrams include both upregulated and downregulated genes. Figure S2. Real-time PCR based validation. Real-time PCR analysis was performed to confirm the microarray results for randomly selected genes a) Stat1, b) Stat2, c) Zfp456, Nt5c2 and NfkB2 post V3000 infection and d) Samd9l post V3000 and V3034 infections. Expression values of all the genes were normalized with the house keeping gene, GAPDH. The results here are representative of 2 biological replicates and 2 technical replicates for each biological replicate. Blue bar: RT-PCR expression level; Red bar: Microarray expression level. Details of primer sets used are given in supplementary table-7. Figure S3. Network analysis of apoptotic genes modulated in response to V3000 and V3034 infections in spleen at $48 \mathrm{~h}$ and $72 \mathrm{~h}$ pi. Genes significantly modulated against V3000 and V3034 infections at $48 \mathrm{~h}$ and $72 \mathrm{~h}$ pi in spleen were used to perform in silico network analysis using the Ingenuity Pathway analysis software. Both the viruses resulted in modulation of apoptosis pathway at $48 \mathrm{~h}$ and $72 \mathrm{~h}$ pi. Figure $\mathbf{S 4}$. Network analysis of inflammatory genes modulated in response to V3000 and V3034 infections in spleen at $48 \mathrm{~h}$ and $72 \mathrm{~h}$ pi. Genes significantly modulated against V3000 and V3034 infections at $48 \mathrm{~h}$ and $72 \mathrm{~h}$ pi in spleen were used to perform in silico network analysis using the Ingenuity Pathway analysis software. Both the viruses resulted in activation of various immune cells to different degrees at $48 \mathrm{~h}$ and $72 \mathrm{~h}$ pi as shown above. (DOCX $1842 \mathrm{~kb}$ ) 
Additional file 2: Table S1. Significantly modulated genes common against V3000 and V3034 strains of VEEV in spleen. Genes that were modulated with both V3000 and V3034 infection in the spleen were identified. The list summarizes the commonly modulated genes for each time point studied. Values are expressed as average values of $\left(\log _{2}\right)$ fold expression for each gene over uninfected controls \pm standard error mean (SEM). * $P \leq 0.05$. (DOCX $45 \mathrm{~kb})$

Additional file 3: Table S2. Significantly modulated genes common against V3000 and V3034 strains of VEEV in brain. Genes that were modulated with both V3000 and V3034 infection in the brain were identified. The list summarizes the commonly modulated genes for each time point studied. Values are expressed as average values of $\left(\log _{2}\right)$ fold expression for each gene over uninfected controls \pm standard error mean (SEM). ${ }^{*} P \leq 0.05$. (DOCX $\left.43 \mathrm{~kb}\right)$

Additional file 4: Table S3. Significantly modulated genes in the spleen that were unique to V3000 infection. Genes that were modulated only with V3000 infection in the spleen were identified. The list summarizes the commonly modulated genes for each time point studied. Values are expressed as average values of $\left(\log _{2}\right)$ fold expression for each gene over uninfected controls \pm standard error mean (SEM). * $P \leq$ 0.05. (DOCX $82 \mathrm{~kb})$

Additional file 5: Table S4. Significantly modulated genes in the brain that were unique to V3000 infection. Genes that were modulated only with V3000 infection in the brain were identified. The list summarizes the commonly modulated genes for each time point studied. Values are expressed as average values of $\left(\log _{2}\right)$ fold expression for each gene over uninfected controls \pm standard error mean (SEM). ${ }^{*} P \leq 0.05$. (DOCX $38 \mathrm{~kb}$ )

Additional file 6: Table S5: Significantly modulated genes in the spleen that were unique to V3034 infection. Genes that were modulated only with V3034 infection in the spleen were identified. The list summarizes the commonly modulated genes for each time point studied. Values are expressed as average values of $\left(\log _{2}\right)$ fold expression for each gene over uninfected controls \pm standard error mean (SEM). * $P \leq 0.05$. (DOCX $50 \mathrm{~kb})$

Additional file 7: Table S6. Significantly modulated genes in the brain that were unique to V3034 infection. Genes that were modulated only with V3034 infection in the brain were identified. The list summarizes the commonly modulated genes for each time point studied. Values are expressed as average values of $\left(\log _{2}\right)$ fold expression for each gene over uninfected controls \pm standard error mean (SEM). * $P \leq 0.05$. (DOCX $29 \mathrm{~kb}$ )

Additional file 8: Table S7. Primer sequences used for real-time PCR. Real-time PCR analysis was performed to confirm the microarray results for Stat1, Stat2, Zfp456, Nt5c2, NfкB2 and Samd9l post V3000 and V3034 infections at various time points. Expression values of all the genes were normalized with the house keeping gene, GAPDH. The details of primer sets used are summarized in this table. (DOCX $14 \mathrm{~kb}$ )

\section{Abbreviations}

CCR5: C-C motif Chemokine Receptor5; CIT: Center for Information Technology; CNS: Central Nervous System; CXCR4: CXC chemokine receptor4; DC: Dendritic Cells; DPBS: Dulbecco's Phosphate Buffered Saline; EMH: Extra Medullary Hematopoiesis; GAPDH: Glyceraldehyde-3-Phosphate Dehydrogenase; H\&E: Hematoxylin and Eosin; H2-T23: Histocompatibility 2, T region locus 23; IL: Interleukins; IPA: Ingenuity Pathway Analysis; IRF: Interferon Regulatory Factor; NIH: National Institutes of Health; NKC: Natural Killer Cells; Pi: Post Infection; PRR: Pattern Recognition Receptors; TCR: T-cell Receptor; TLR: Toll Like Receptors; TNFR1: Tumor Necrosis Factor Receptor1; TSA-1: Thymic Shared Antigen-1; VCAM: Vascular Cell Adhesion protein; VEEV: Venezuelan Equine Encephalitis Virus

\section{Acknowledgements}

Disclaimer: The opinions and the views expressed herein are those of the author(s), and are not necessarily representative of those of the Uniformed Services University of the Health Sciences, the Food and Drug Administration, the Department of Defense (DOD), the United States Army, Navy; or Air Force, nor does mention of trade names, commercial products or organizations imply endorsement by the US Government.

\section{Funding}

These studies were supported by funding from Defense Threat Reduction Agency to RKM. The funding agency had no role in the design of the study and collection, analysis, and interpretation of data and in writing the manuscript.

\section{Availability of data and materials}

All the datasets supporting our findings are included within the manuscript and the supplementary files. The microarray data discussed in this publication have been deposited in NCBI's Gene Expression Omnibus [50] and are accessible through GEO Series accession number GSE96550 (https://www.ncbi.nlm.nih.gov/geo/query/acc.cgi?acc=GSE96550).

\section{Authors' contributions}

PG carried out the RNA isolation, microarrays, PCRs, histological staining and the data analysis. AS performed the tissue collections and histological analysis. BKR read the H\&E and immuno-stained tissue sections, PG and AS wrote the manuscript. MB helped in RNA isolations. $\mathrm{JH}, \mathrm{AY}$ and RKP printed and provided the microarray slides for the experiments, participated in data analysis, and edited the manuscript. RKM supervised the study design, coordinated in conducting the experiments and helped to draft the manuscript All authors read and approved the final manuscript- Dr. Maheshwari approved an earlier version of the manuscript prior to his untimely death.

\section{Competing interests}

The authors declare that they have no competing interests.

\section{Consent for publication}

Not applicable.

\section{Ethics approval}

The animal experiments with virulent VEEV were conducted in bio-safety level-3 facility at USUHS during the time frame when USUHS was registered with the CDC select agent program. Data analysis and manuscript preparation were completed afterwards. Animals were housed in a facility fully accredited by the Association for Assessment and Accreditation of Laboratory Animal Care (AAALAC)-International and treated in accordance with the guidelines from the Guide for the Care and Use of Laboratory Animals of the Institute for the Laboratory Animal Research, National Research Council. Mice were housed in microisolator cages and were provided food and water ad libitum with a $12 \mathrm{~h}$ light/dark cycle. All the animal handling and euthanasia protocols were reviewed and approved by the Institutional Animal Care and Use Committees. The study summarized here does not contain any patient data.

\section{Publisher's Note}

Springer Nature remains neutral with regard to jurisdictional claims in published maps and institutional affiliations.

\section{Author details}

${ }^{1}$ Department of Pathology, Uniformed Services University of the Health Sciences, 4301 Jones Bridge Road, Bethesda, MD 20814, USA. Division of Cellular and Gene Therapies, Center for Biologics Evaluation and Research, Food and Drug Administration, Bethesda, MD, USA.

Received: 20 February 2016 Accepted: 28 March 2017

Published online: 26 April 2017

\section{References}

1. Ryzhikov AB, Tkacheva NV, Sergeev AN, Ryabchikova El. Venezuelan equine encephalitis virus propagation in the olfactory tract of normal and immunized mice. Biomedical science. 1991;2(6):607-14.

2. Charles PC, Walters E, Margolis F, Johnston RE. Mechanism of neuroinvasion of Venezuelan equine encephalitis virus in the mouse. Virology. 1995;208(2): $662-71$

3. Grieder FB, Davis NL, Aronson JF, Charles PC, Sellon DC, Suzuki K, Johnston RE. Specific restrictions in the progression of Venezuelan equine encephalitis virus-induced disease resulting from single amino acid changes in the glycoproteins. Virology. 1995;206(2):994-1006.

4. Weaver SC, Ferro C, Barrera R, Boshell J, Navarro JC. Venezuelan equine encephalitis. Annu Rev Entomol. 2004;49:141-74. 
5. Steele KE, Twenhafel NA. REVIEW PAPER: pathology of animal models of alphavirus encephalitis. Vet Pathol. 2010;47(5):790-805.

6. Schoneboom BA, Catlin KM, Marty AM, Grieder FB. Inflammation is a component of neurodegeneration in response to Venezuelan equine encephalitis virus infection in mice. J Neuroimmunol. 2000;109(2):132-46.

7. Schoneboom BA, Lee JS, Grieder FB. Early expression of IFN-alpha/beta and iNOS in the brains of Venezuelan equine encephalitis virus-infected mice. Journal of interferon \& cytokine research. 2000;20(2):205-15.

8. Sharma A, Bhattacharya B, Puri RK, Maheshwari RK. Venezuelan equine encephalitis virus infection causes modulation of inflammatory and immune response genes in mouse brain. BMC Genomics. 2008;9:289.

9. Sharma A, Bhomia M, Honnold SP, Maheshwari RK. Role of adhesion molecules and inflammation in Venezuelan equine encephalitis virus infected mouse brain. Virol J. 2011;8:197.

10. Sharma A, Maheshwari RK. Oligonucleotide array analysis of Toll-like receptors and associated signalling genes in Venezuelan equine encephalitis virus-infected mouse brain. The Journal of general virology. 2009;90(Pt 8):1836-47.

11. Pastorino B, Nougairede A, Wurtz N, Gould E, de Lamballerie X. Role of host cell factors in flavivirus infection: Implications for pathogenesis and development of antiviral drugs. Antiviral Res. 2010;87(3):281-94.

12. Charles PC, Trgovcich J, Davis NL, Johnston RE. Immunopathogenesis and immune modulation of Venezuelan equine encephalitis virus-induced disease in the mouse. Virology. 2001;284(2):190-202.

13. Abella V, Scotece M, Conde J, Gomez R, Lois A, Pino J, Gomez-Reino JJ, Lago F, Mobasheri A, Gualillo O. The potential of lipocalin-2/NGAL as biomarker for inflammatory and metabolic diseases. Biomarkers. 2015;20(8): 565-71

14. Steele KE, Seth P, Catlin-Lebaron KM, Schoneboom BA, Husain MM, Grieder $F$, Maheshwari RK. Tunicamycin enhances neuroinvasion and encephalitis in mice infected with Venezuelan equine encephalitis virus. Vet Pathol. 2006; 43(6):904-13.

15. Jackson AC, SenGupta SK, Smith JF. Pathogenesis of Venezuelan equine encephalitis virus infection in mice and hamsters. Vet Pathol. 1991;28(5): $410-8$.

16. Schoneboom BA, Fultz MJ, Miller TH, McKinney LC, Grieder FB. Astrocytes as targets for Venezuelan equine encephalitis virus infection. Journal of neurovirology. 1999;5(4):342-54.

17. Tantawy MA, Hatesuer B, Wilk E, Dengler L, Kasnitz N, Weiss S, Schughart K. The interferon-induced gene Ifi27l2a is active in lung macrophages and lymphocytes after influenza A infection but deletion of Ifi2712a in mice does not increase susceptibility to infection. PloS one. 2014;9(9):e106392.

18. Weidner JM, Jiang D, Pan XB, Chang J, Block TM, Guo JT. Interferon-induced cell membrane proteins, IFITM3 and tetherin, inhibit vesicular stomatitis virus infection via distinct mechanisms. J Virol. 2010;84(24):12646-57.

19. Koterski J, Twenhafel N, Porter A, Reed DS, Martino-Catt S, Sobral B, Crasta O, Downey T, DaSilva L. Gene expression profiling of nonhuman primates exposed to aerosolized Venezuelan equine encephalitis virus. FEMS immunology and medical microbiology. 2007;51(3):462-72.

20. Mudhasani R, Tran JP, Retterer C, Radoshitzky SR, Kota KP, Altamura LA, Smith JM, Packard BZ, Kuhn JH, Costantino J, et al. IFITM-2 and IFITM-3 but not IFITM-1 restrict Rift Valley fever virus. J Virol. 2013;87(15):8451-64.

21. Zhu X, He Z, Yuan J, Wen W, Huang X, Hu Y, Lin C, Pan J, Li R, Deng H, et al. IFITM3-containing exosome as a novel mediator for anti-viral response in denque virus infection. Cellular microbiology. 2015;17(1):105-18.

22. Meliopoulos VA, Andersen LE, Brooks P, Yan X, Bakre A, Coleman JK, Tompkins SM, Tripp RA. MicroRNA regulation of human protease genes essential for influenza virus replication. PloS one. 2012;7(5):e37169.

23. Lee JK, Shin JH, Hwang SG, Gwag BJ, McKee AC, Lee J, Kowall NW, Ryu H, Lim DS, Choi EJ. MST1 functions as a key modulator of neurodegeneration in a mouse model of ALS. Proc Natl Acad Sci U S A. 2013;110(29):12066-71.

24. Maejima Y, Kyoi S, Zhai P, Liu T, Li H, Ivessa A, Sciarretta S, Del Re DP, Zablocki $\mathrm{DK}$, Hsu CP, et al. Mst1 inhibits autophagy by promoting the interaction between Beclin1 and BCl-2. Nature medicine. 2013;19(11):1478-88.

25. Jiang D, Weidner JM, Qing M, Pan XB, Guo H, Xu C, Zhang X, Birk A, Chang J, Shi PY, et al. Identification of five interferon-induced cellular proteins that inhibit west nile virus and dengue virus infections. J Virol. 2010;84(16):8332-41.

26. John SP, Chin CR, Perreira JM, Feeley EM, Aker AM, Savidis G, Smith SE, Elia $A E$, Everitt AR, Vora M, et al. The CD225 domain of IFITM3 is required for both IFITM protein association and inhibition of influenza $A$ virus and dengue virus replication. J Virol. 2013;87(14):7837-52.
27. Gao D, Zhai A, Qian J, Li A, Li Y, Song W, Zhao H, Yu X, Wu J, Zhang Q, et al. Down-regulation of suppressor of cytokine signaling 3 by miR-122 enhances interferon-mediated suppression of hepatitis B virus. Antiviral Res. 2015:118:20-8.

28. Choi EJ, Lee CH, Shin OS. Suppressor of Cytokine Signaling 3 expression induced by Varicella-Zoster Virus infection results in the modulation of virus replication. Scandinavian journal of immunology. 2015;82:337-44.

29. Stamatovic SM, Shakui P, Keep RF, Moore BB, Kunkel SL, Van Rooijen N, Andjelkovic AV. Monocyte chemoattractant protein-1 regulation of bloodbrain barrier permeability. Journal of cerebral blood flow and metabolism. 2005;25(5):593-606.

30. Eugenin EA, Dyer G, Calderon TM, Berman JW. HIV-1 tat protein induces a migratory phenotype in human fetal microglia by a CCL2 (MCP-1)dependent mechanism: possible role in NeuroAIDS. Glia. 2005;49(4):501-10.

31. Zink MC, Coleman GD, Mankowski JL, Adams RJ, Tarwater PM, Fox K, Clements JE. Increased macrophage chemoattractant protein-1 in cerebrospinal fluid precedes and predicts simian immunodeficiency virus encephalitis. J Infect Dis. 2001;184(8):1015-21.

32. Mangus LM, Dorsey JL, Laast VA, Hauer P, Queen SE, Adams RJ, McArthur $J C$, Mankowski JL. Neuroinflammation and virus replication in the spinal cord of simian immunodeficiency virus-infected macaques. Journal of neuropathology and experimental neurology. 2015;74(1):38-47.

33. Martin SS, Bakken RR, Lind CM, Garcia P, Jenkins E, Glass PJ, Parker MD, Hart $M K$, Fine DL. Evaluation of formalin inactivated V3526 virus with adjuvant as a next generation vaccine candidate for Venezuelan equine encephalitis virus. Vaccine. 2010;28(18):3143-51.

34. Kanno M, Suzuki S, Fujiwara T, Yokoyama A, Sakamoto A, Takahashi H, Imai Y, Tanaka J. Functional expression of CCL6 by rat microglia: a possible role of CCL6 in cell-cell communication. J Neuroimmunol. 2005;167(1-2):72-80.

35. Asensio VC, Lassmann S, Pagenstecher A, Steffensen SC, Henriksen SJ, Campbell IL. C10 is a novel chemokine expressed in experimental inflammatory demyelinating disorders that promotes recruitment of macrophages to the central nervous system. The American journal of pathology. 1999;154(4):1181-91.

36. Garcia-Tapia D, Hassett DE, Mitchell Jr WJ, Johnson GC, Kleiboeker SB. West Nile virus encephalitis: sequential histopathological and immunological events in a murine model of infection. Journal of neurovirology. 2007;13(2):130-8.

37. Mallya M, Campbell RD, Aguado B. Transcriptional analysis of a novel cluster of LY-6 family members in the human and mouse major histocompatibility complex: five genes with many splice forms. Genomics. 2002;80(1):113-23.

38. Hijazi A, Haenlin M, Waltzer L, Roch F. The Ly6 protein coiled is required for septate junction and blood brain barrier organisation in Drosophila. PloS one. 2011;6(3):e17763.

39. Jutila MA, Kroese FG, Jutila KL, Stall AM, Fiering S, Herzenberg LA, Berg EL, Butcher EC. Ly-6C is a monocyte/macrophage and endothelial cell differentiation antigen regulated by interferon-gamma. European journal of immunology. 1988;18(11):1819-26.

40. Bamezai A, Rock KL. Overexpressed Ly-6A.2 mediates cell-cell adhesion by binding a ligand expressed on lymphoid cells. Proc Natl Acad Sci U S A. 1995;92(10):4294-8.

41. Bamezai A, Palliser D, Berezovskaya A, McGrew J, Higgins K, Lacy E, Rock KL. Regulated expression of $L y-6 A .2$ is important for T cell development. J Immunol. 1995:154(9):4233-9.

42. Saitoh S, Kosugi A, Noda S, Yamamoto N, Ogata M, Minami Y, Miyake K, Hamaoka T. Modulation of TCR-mediated signaling pathway by thymic shared antigen-1 (TSA-1)/stem cell antigen-2 (Sca-2). J Immunol. 1995; 155(12):5574-81.

43. Mao W, Hunt HD, Cheng HH. Cloning and functional characterization of chicken stem cell antigen 2. Developmental and comparative immunology. 2010;34(3):360-8.

44. Classon BJ, Boyd RL. Thymic-shared antigen-1 (TSA-1). A lymphostromal cell membrane Ly-6 superfamily molecule with a putative role in cellular adhesion. Developmental immunology. 1998;6(1-2):149-56.

45. Feng $X$, Huang J, Liu Y, Xiao L, Wang D, Hua B, Tsao BP, Sun L. Identification of interferon-inducible genes as diagnostic biomarker for systemic lupus erythematosus. Clinical rheumatology. 2015;34(1):71-9.

46. Ou R, Zhang M, Huang L, Flavell RA, Koni PA, Moskophidis D. Regulation of immune response and inflammatory reactions against viral infection by VCAM-1. J Virol. 2008;82(6):2952-65.

47. Taylor K, Kolokoltsova O, Patterson M, Poussard A, Smith J, Estes DM, Paessler S. Natural killer cell mediated pathogenesis determines outcome of 
central nervous system infection with Venezuelan equine encephalitis virus in C3H/HeN mice. Vaccine. 2012;30(27):4095-105.

48. Kulcsar KA, Baxter VK, Abraham R, Nelson A, Griffin DE. Distinct Immune Responses in Resistant and Susceptible Strains of Mice during Neurovirulent Alphavirus Encephalomyelitis. J Virol. 2015;89(16):8280-91.

49. Yang AX, Mejido J, Bhattacharya B, Petersen D, Han J, Kawasaki ES, Puri RK. Analysis of the quality of contact-pin fabricated oligonucleotide microarrays. Mol Biotechnol. 2006;34(3):303-15.

50. Edgar R, Domrachev M, Lash AE. Gene Expression Omnibus: NCBI gene expression and hybridization array data repository. Nucleic acids research. 2002:30(1):207-10

Submit your next manuscript to BioMed Central and we will help you at every step:

- We accept pre-submission inquiries

- Our selector tool helps you to find the most relevant journal

- We provide round the clock customer support

- Convenient online submission

- Thorough peer review

- Inclusion in PubMed and all major indexing services

- Maximum visibility for your research

Submit your manuscript at www.biomedcentral.com/submit 